\title{
EL DEBER PRECONTRACTUAL DE INFORMACIÓN EN EL CONTRATO DE SEGURO, UN PRODUCTO FINANCIERO Y DE CONSUMO. ESTUDIO DE SUS FUENTES*
}

\author{
PRECONTRACTUAL DUTY OF INFORMATION IN INSURANCE AS A \\ FINANCIAL PRODUCT.A STUDY OF HISTORICAL LEGAL SOURCES
}

\section{Marcelo Barrientos Zamorano ${ }^{*}$}

\begin{abstract}
RESUMEN: Este trabajo versa sobre las fuentes normativas relativas a los deberes precontractuales en el contrato de seguro, desde el punto de vista del deber precontractual de información, conforme a las modificaciones legales de la Ley de Protección de Consumidores, por la Ley No 20.555 y en el Código de Comercio, por la ley 20.667.
\end{abstract}

Palabras clave: Seguros, deber precontractual de información, consumo.

ABSTRACT: This paper deals with the rules on pre-contractual duties in insurance contract sources, from the point of view of pre-contractual information duties, in accordance with legal amendments of the Chilean's Consumer Law Protection and in the Chilean's Commercial Code.

Key words: Insurance, precontractual information duties, Consumer Law.

\section{INTRODUCCIÓN. CONCEPTOS PREVIOS PARA UNA ADECUADA DISCUSIÓN}

A partir de hace poco más de un año, la aprobación de la ley 20.667, publicada el 9 de mayo de 2013, dotó al ordenamiento jurídico chileno de una nueva regulación del contrato de seguro en el Código de Comercio (en adelante CCOM), legislación que se une a la Ley 19.496, de protección de consumidores (en adelante, LPC) modificada a su vez por la ley $20.555^{1}$, que introduce nuevos derechos para los asegurados consumidores, y que con-

\footnotetext{
Abogado. Profesor de Derecho Civil de la Pontificia Universidad Católica de Chile. Doctor en Derecho con mención "Doctor Europeus", Universidad de Salamanca, España. Magíster en Derecho de la Empresa, Pontificia Universidad Católica de Chile. Dirección postal: Av. Libertador Bernardo O’Higgins 340, Santiago, Chile. Dirección electrónica: mhbz@uc.cl

" Este trabajo forma parte de la investigación que se realiza en el marco del Proyecto de Investigación: Fondecyt Regular $N^{\circ} 1141220$, titulado "El contrato de seguro como contrato de consumo. Examen crítico de su estructura y sistematización después de las reformas de la ley de protección del consumidor y el Código de Comercio". Este artículo también forma parte del proyecto de investigación que recibe las "Ayuda a la Investigación 2012" de la Fundación Mapfre en el marco del proyecto "Formación del contrato de seguro en la nueva ley del consumidor chilena y su última modificación del 2011, ley 20.555”. Por último, también forma parte del proyecto Anillo-CONICYT código SOC 1111. El autor desea expresar su agradecimiento a la colaboración prestada, en la investigación de las fuentes de este trabajo, a los ayudantes alumnos de la facultad de derecho de la Pontificia Universidad Católica de Chile: Ricardo Ihle, Juan Vidal y Adriana Villamizar. Asimismo, doy mis agradecimientos a la abogada Stefanie Ramdohr Montgomery y el Prof. Dr. Roberto Ríos Ossa, por sus valiosas aportaciones en estos temas a lo largo de los años de investigación en la materia.

1 El Código de comercio chileno fue modificado mediante la Ley 20.667 publicada en el Diario Oficial (en adelante D.O) el 9 de mayo del 2013. La referida ley tuvo una vacancia legal. El artículo transitorio de esta ley,
} 
sidera a los seguros como productos financieros, a partir de diciembre de 2011. Como consecuencia de estas reformas los contratos de seguro, importantes contratos del tráfico jurídico, deben ser considerados como contratos estandarizados y deben regirse también por la ley del consumidor ${ }^{2}$. Demostraremos este acerto, ofreciendo una visión general del estudio de las fuentes normativas de ambas leyes y los modelos que fueron tenidos en cuenta por el legislador en relación al deber precontractual de información.

Concurre, adelantamos, una clara duplicidad normativa sobre el contrato de seguro actualmente, ya que en la mente del legislador, como en las reformas finalmente aprobadas, hay un expreso reconocimiento de que el asegurado es un consumidor. Al menos, así se declara. En efecto, los nuevos artículos del Título VIII del Libro II del CCOM, plantean un nuevo escenario para el deber de información precontractual del contrato de seguro, escenario complejo por cuanto existe superabundancia de su regulación, tanto legal, administrativa, como convencional ${ }^{3}$. El anterior artículo 512 del Código de Comercio que establecía que el contrato seguro era bilateral, condicional y aleatorio, debe dejarse en la historia del derecho ${ }^{4}$. En cualquier caso, cada vez que en este texto de haga referencia a los artículos del Código de Comercio, se debe entender que se refieren a los actualmente vigentes e introducidos por la ley 20.667 .

señalaba: "La presente ley comenzará a regir el primer día del séptimo mes siguiente al de su publicación". La historia de la norma se encuentra disponible en: www.leychile.cl [fecha de consulta: 6 de julio de 2014].

${ }^{2}$ Recordemos que en el ordenamiento jurídico chileno, la comercialización masiva de pólizas estandarizadas se supedita a los modelos de condicionados generales depositados en la Superintendencia de Valores y Seguros, según lo exige la letra f) del artículo 3 del Decreto con Fuerza de Ley número 251. Representa esta una antigua norma de la reglamentación legal de seguros, seriamente cuestionada luego de la reforma de la ley 20.667, a nuestro juicio, especialmente por el carácter imperativo del artículo 542 del Código de Comercio que consagra reglas de imperatividad. Solo para que usted se haga una idea de la importancia de este tipo de contratos en el tráfico económico chileno, el mercado asegurador chileno representa un poco más del $2.4 \%$ del PIB nacional. La prima per cápita promedio en Chile alcanzó, en el período 2012 a 2013, a los $\$ 373.464$ (€ 494 por cada habitante) y el volumen total de primas del mismo ejercicio arrojó un total de 239 millones de UF intermediadas (8.623 millones de €), lo que representa un 6.2\% más que el año anterior. Solo el seguro de vida tuvo un ingreso general, por concepto de primas, de 143 millones de UF (5.152 millones de $€$ o si se prefiere $\$ 3.889 .800 .000$ de pesos). El PIB chileno alcanza los 207.730 millones de euros. FundaCión MAPFrE (2013), pp. 63 y siguientes. ${ }^{3}$ La historia de la norma se encuentra disponible en: www.leychile.cl [fecha de consulta: 26 de junio 2014]. pp. 9.

${ }^{4}$ El Título VIII comprende desde el artículo 512 hasta el 601 del Código de Comercio, divididos en tres secciones. En la Sección Primera se contienen las Normas Comunes a todo tipo de seguros. La Sección Segunda, referida a Seguros de Daños, comprende los subtítulos: 1. Normas Generales; 2. Del Seguro contra Incendio; 3. De los Seguros de Robo, Hurto y otras sustracciones; 4. Del Seguro de Responsabilidad Civil; 5. Del Seguro de Transporte Terrestre; 6. Del Seguro de Pérdida de Beneficios; 7. Del Seguro de Crédito; 8. Del Seguro de Caución, y 9. Del Contrato de Reaseguro. La Sección Tercera está referida a Seguros de Personas. En diciembre de 2003 el ministro de Justicia designó un grupo de trabajo, integrado por cuatro abogados de la especialidad, con el encargo de revisar nuevamente el proyecto y actualizar sus disposiciones. En el segundo semestre de 2004 se hizo entrega al ministro del texto modificado, el que fue analizado durante los meses siguientes en el seno de una comisión constituida por abogados de la Superintendencia y los integrantes del referido grupo de trabajo. Ello no generó el despacho de un nuevo proyecto, aunque el texto final se constituyó en la base de la iniciativa que dos años después surgió en la Cámara de Diputados, la que culminó con la promulgación de la Ley No 20.667. Arellano, Sergio (2013) pp. 7. El Contrato de Seguro, además de la regulación propia del artículo 512 y siguientes del Código de Comercio, que empezó a regir el uno de diciembre de 2013, ha estado durante mucho tiempo regulado también por el DFL 251 de 1931, el que deberá ser modificado y reinterpretado, sino legalmente para el primer caso, jurisprudencialmente para el segundo,puesto que debe armonizarse con la nueva normativa de las leyes del consumidor y el propio Código de Comercio, en lo que a contrato de seguros privados, al menos, se refiere. 
Ya en el propio mensaje de la ley 20.555, que modificó la ley de consumidores se declaraba: "las modificaciones específicas contenidas en este proyecto de ley, son las siguientes:

1. Mejorar las condiciones para que los consumidores puedan acceder a la información sobre los productos y servicios que se les ofrecen, principalmente mejorando los canales de información a través de Internet" 5 .

A su tiempo, en la tramitación de las mociones que dieron origen a la ley 20.667, que modificó el Título VIII del Libro II del Código de Comercio, se expresaba:"Este proyecto viene, así, a continuar el camino abierto por otras iniciativas legales recientes de gran importancia en materias propias del derecho comercial y económico, que ya se han materializado, como las modificaciones a la ley de protección al consumidor, a la ley de defensa de la libre competencia, la ley sobre arbitraje comercial internacional y la ley sobre la competencia desleal”.

Nuestro artículo intentará hacerse cargo de las fuentes normativas relativas a los deberes precontractuales en el contrato de seguro, abordadas desde la óptica del consumidor de seguros privados, y será desarrollado de la siguiente manera:

1. Los problemas de asimetría de información precontractual en el seguro.

A. El abandono de la libertad contractual total en la creación del contrato de seguro.

2. Modificación del deber precontractual de información en el contrato de seguro, en la LPC chilena, por la Ley No 20.555 y en el CCOM, ley 20.667. Aspectos generales.

A. La posible influencia de la legislación de los EE.UU. en la ley 20.555, que modificó la ley de protección de consumidores en el deber precontractual de información.

B. La legislación europea tenida en cuenta en el cambio legislativo chileno del deber precontractual de información.

i. La Directiva 2002/65/CE del Parlamento Europeo y el Consejo en la génesis de la ley 20.555 y el deber precontractual de información.

ii. La reforma inglesa: Financial Services Act y su influencia en la reforma chilena de seguros y el deber precontractual de información.

iii. La ley española de seguros como fuente del deber de información precontractual en la ley 20.667.

iv. La reforma alemana de seguros de 2008 y su influencia en el deber de información precontractual en la ley 20.667.

Conclusiones.

\section{LOS PROBLEMAS DE ASIMETRÍA DE INFORMACIÓN PRECONTRACTUAL EN EL SEGURO}

En materia de seguros es sabido que interactúan normas de derecho privado y público. En esta área del derecho conviven y transitan intervenciones directas del Estado sobre la actividad de las compañías de seguros y los asegurados. Hay que considerar en este sentido, además, que todo el mercado de seguros se mueve entre el mercado de valores, el mercado

${ }^{5}$ La historia de la norma se encuentra disponible en: www.leychile.cl [fecha de consulta: 6 de julio 2014] pp. 5. 
financiero, el derecho comercial, el derecho del consumo, y en fin, dentro de la esfera del derecho privado.

No es de extrañar entonces que el impacto de la reforma se haya hecho sentir con fuerza en un mercado de seguros acostumbrado a una regulación completamente distinta y más cercana a la tradicional forma de contratación, ligada a los principios de autonomía de voluntad y libertad contractual, sin perjuicio de que en clave moderna la industria del seguro desde hace bastante tiempo ha recurrido a formas de contratación propia de condiciones generales de contratación. Desde este punto de vista, la actual legislación, tanto de la ley del consumidor como la del Código de Comercio, solo sincera una realidad práctica contractual de larga data ${ }^{6}$.

Reflejo de lo anterior es el impacto en la industria aseguradora producido después de la dictación, a fines del año 2013, por parte de la Superintendencia de Valores y Seguros (en adelante SVS) de la Norma de Carácter General (en adelante NCG) 347 , que dio lugar a nuevos depósitos de condicionados generales o productos de seguros inexistentes hasta la fecha por parte de las compañías de seguros chilenas. Esta norma fue dictada, según lo dispuesto en el artículo 40 del D.F.L. N ${ }^{\circ} 251$, de 1931, y las facultades que confiere la ley a las Superintendencias de Valores y Seguros y de Bancos e Instituciones Financieras. Son estas instrucciones de cumplimiento obligatorio para los bancos, cooperativas, agentes administradores de mutuos hipotecarios endosables, cajas de compensación de asignación familiar y cualquier otra entidad que tenga dentro de su giro otorgar créditos hipotecarios, y a las Compañías de Seguros de Vida y de Seguros Generales. Para los efectos de esta norma reglamentaria, también son consideradas entidades crediticias las sociedades inmobiliarias, respecto de los seguros que deban contratar en virtud de los contratos de arrendamiento de vivienda con promesa de compraventa, celebrados en conformidad a lo dispuesto en la ley $\mathrm{N}^{\circ} 19.281$.

En consecuencia, en materia de contratación de seguros, se plantea ahora la necesidad de definir nuevas reglas de trato entre las compañías de seguros y los tomadores de los seguros, es decir, frente a los consumidores de estos productos. Es cierto que en la gran mayoría de los casos la condición de "tomador del seguro" y la de "asegurado" recaen en la misma persona, pero no es necesariamente así, ya que, por ejemplo, en los seguros de vida el tomador

\footnotetext{
${ }^{6}$ De hecho, así se expresó durante la tramitación legislativa en el congreso de la ley 20.667. La Coordinadora de Mercado de Capitales del Ministerio de Hacienda de la época, señorita Celedón, acotó que: "en los seguros masivos se está en presencia de los denominados contratos de adhesión. Los otros casos corresponden, por ejemplo, a la necesidad que una empresa tiene de asegurar una planta de operaciones, para lo que define cuáles son las coberturas que requiere y realiza una propuesta a un asegurador. Aquí es donde se insertaría el segundo inciso de la indicación en estudio, para que una vez hecha la propuesta, desde el asegurador llegue al tomador un delineamiento del producto que va a contratar. Osvaldo Contreras expuso que, normalmente, la propuesta de celebración se verifica con ocasión de los seguros individuales, en que el asegurado, en base a un cuestionario que le proporciona la compañía, le indica al asegurador qué cobertura requiere. Algo distinto acontece en otros contratos de seguros, en que una empresa grande llama a las aseguradoras a competir para adjudicarse su cartera de seguros. Y una tercera alternativa se verifica con ocasión de los seguros colectivos. A su entender, expresó, la redacción del artículo 514 se refiere solamente al primero de estos casos, en consonancia con la definición de propuesta del artículo 513". La historia de la norma se encuentra disponible en: www.leychile.cl [fecha de consulta: 5 de junio de 2014]. pp. 382.

7 Ver en depósito de pólizas www.svs.cl [fecha de consulta: 20 de mayo de 2014]. La NCG 347 tiene vigencia desde el 1 de julio de 2013 y se aplica a todas las licitaciones que deban iniciarse a contar de esa fecha. Disponible en www.svs.cl [fecha de consulta 5 de mayo de 2014)].
} 
y asegurado pueden ser personas distintas por lo que tenemos necesariamente que hacer los matices oportunos para entender qué derechos y cargas les corresponden a unos u otros ${ }^{8}$.

Un primer elemento a tener en cuenta en el marco de la nueva ley de contratos de seguros, tal como sucede en la experiencia comparada, es que el asegurador selecciona técnica, matemática y comercialmente qué riesgos le interesa asumir ${ }^{9}$. Lo propio de un seguro es la comunidad de riesgos o mecanismo de transferencia de riesgos que está detrás de él. Esas primas que conforman el fondo patrimonial permiten, entre otras cosas, hacer frente a las indemnizaciones por la ocurrencia de siniestros cubiertos que afectan a la misma comunidad ${ }^{10}$.

Aquí, palmariamente, llamamos desde ya a una reflexión que parece no estar presente en la historia de la norma que se ha cambiado en la legislación chilena, con la fuerza que debiera haberse tomado en cuenta, y es que no todas las compañías de seguro son iguales ${ }^{11}$.

En efecto, hay aseguradores que asumen riesgos masivos, altamente estandarizados en su clausulado, como los seguros de vehículos motorizados, de casa habitación asociados a créditos hipotecarios, y otros que cubren riesgos especiales y que dependen en su abrumadora mayoría de las características caso a caso, como los seguros de vida. La misma circunstancia no es predicable de los riesgos masivos o mayores o grandes riesgos o política de suscripción de riesgos ${ }^{12}$.

Es para tener en cuenta la opinión que, desde la propia discusión de la ley, precisamente en el correspondiente Informe de la Comisión de Economía, Fomento y Desarrollo de la Cámara de Diputados durante la tramitación de la ley 20.667, formulaba el Superintendente de Valores y Seguros al afirmar que: "Siguiendo las tendencias modernas (...) es el asegurador quien debe consultar al pequeño asegurado las circunstancias necesarias para evaluar y suscribir el riesgo. Esto parte del supuesto que es el asegurador quien en realidad conoce, más que el asegurado, los antecedentes necesarios para evaluar el riesgo"13.

Veamos cómo ha cambiado esta forma de contratar.

\footnotetext{
${ }^{8}$ En el Diccionario Mapfre de los seguros se expresa que "Contratante (contracting party) es una persona que suscribe con una entidad aseguradora una póliza o contrato de seguro; equivale a mutualista en una sociedad mutua. Generalmente su personalidad coincide con la del asegurado o la del tomador (del seguro)". Disponible en http://www.mapfre.com/wdiccionario/terminos/vertermino.shtml?c/contratante.htm [fecha de consulta: 19 de julio de 2014.] Mientras que "Tomador del seguro (policy holder) es la persona que contrata el seguro al asegurador, y se obliga al pago de la prima. Frecuentemente es también el asegurado". Disponible en http://www. mapfre.com/wdiccionario/terminos/vertermino.shtml?t/tomador-del-seguro.htm[fecha de consulta: 19 de julio de 2014].

${ }^{9}$ El contrato de seguro reviste particularidades especiales. Una de ellas, está representada sus dimensiones técnica y económica. Los aseguradores se apoyan de una serie de instrumentos extrajurídicos de evaluación de riesgos que hacen viable su operación económica. Sobre lo anterior, VoLPE al referirse al seguro como operación económica, señala que tal operación "consiste en una garantía en contra de las consecuencias patrimoniales dañosas de un riesgo determinado, repartiéndolo entre una pluralidad de sujetos expuestos al mismo riesgo" Volpe (2006) p. 4. En el mismo sentido, véanse Lambert-Faivre y Leveneur (2005) p. 41; Del Caño (1983) p. 434.

10 Rubio (2003) p. 15.

11 Véanse análisis que se hace en el derecho comparado, por citar algunos, Del Caño (1983) p. 436; Elguero (2004) pp. 9 y ss.

12 Sobre la clasificación de los riesgos véanse: GarRigues, Joaquín (1982) pp. 10; Bataller, Juan et al. (2007) p. 154 y ss.

${ }^{13}$ Ley publicada en el Diario Oficial (en adelante D.O.) el 9 de mayo del 2013. La historia de la norma se encuentra disponible en: www.leychile.cl [fecha de consulta: 10 de septiembre de 2013] pp. 73
} 
El hoy derogado artículo 512 del Código de Comercio chileno (en adelante CCOM) definía el contrato de seguro a partir de la concepción liberal del contrato, que se funda en una igualdad abstracta de los contratantes, lo que permitía a cada una de ellas defender por sí misma sus propios intereses. Este proceso se cimentaba en un principio elevado a la categoría de ficción jurídica: un contrato no podría nunca ser injusto ni abusivo, ya que el libre juego de las fuerzas económicas produce siempre lo mejor: necesariamente un resultado justo, Quit dit contractuel, dit juste ${ }^{14}$.

La jurisprudencia chilena en estas materias, en el marco de la legislación hoy derogada, siempre entendió que el contrato de seguro y los derechos y obligaciones que de él provienen eran regidos, en primer lugar, por las normas y cláusulas que las propias partes habían convenido en el contrato respectivo. Se aplicaba en su integridad a este respecto el principio de la libertad contractual consagrado en el artículo 1545 del Código Civil, según el cual, todo contrato legalmente celebrado es una ley para los contratantes y no puede ser invalidado, sino por consentimiento mutuo o por causas legales.

A falta de una estipulación expresa de las partes, y en forma supletoria, se aplicaban, en primer lugar, las normas especiales, hoy derogadas, que regulaban el respectivo contrato de seguro, como sucedía con los artículos 569 a 578 del Código de Comercio respecto del seguro de vida; con los artículos 579 a 586, respecto del seguro de incendio; con los artículos 587 a 590, respecto a los seguros agrícolas; con los artículos 591 a 601, respecto del seguro de transporte terrestre y los artículos 1158 a 1202 del Código de Comercio, respecto de los seguros marítimos.

Luego, en este tipo de contratos, quedaban relegados a un segundo plano las normas correspondientes a leyes especiales relativas a los seguros terrestres -todos aquellos que no son marítimos- que estaban comprendidas en los artículos 561 a 568 del Código de Comercio.

Finalmente, en una tercera categoría de normas se ocupaban, cual prelación, las disposiciones comunes a toda clase de seguros terrestres y marítimos, consagrados en los artículos 512 y 560 del mismo cuerpo legal ${ }^{15}$.

También se aplicaban, pero ya no en forma supletoria, sino específica, y principalmente en las materias pertinentes del respectivo contrato de seguro, las disposiciones contenidas en el Decreto con Fuerza de Ley No 251 de 1931 que, junto con regular la actividad comercial de los seguros, contiene todavía hoy reglas que se relacionan directamente con el contrato y sus efectos. Entre estas reglas, se puede mencionar las que obligan al registro público de los modelos de póliza, del artículo $3^{\circ}$ letra e) del Decreto con Fuerza de Ley No $251^{16}$.

\footnotetext{
${ }^{14}$ Sobre el desarrollo de estas ideas, lo desarrollado en BARRIEnTOS (2008) pp. 49 y ss.

15 Sobre estas ideas, el lúcido análisis que para el deber precontractual de declaración del riesgo hace Ríos (2014) pp. 20 y ss.

16 De esta manera, de acuerdo a las Circulares de la SVS, cabe mencionar la número 1457 de 1999, que determinaba la información que debía incluir la póliza de seguros, modificada por la reciente Circular 2123, de 22 de octubre de 2013, que imparte instrucciones sobre: información a incluir en pólizas de seguros; información de las primas y comisiones; reglas para seguros contratados en forma colectiva; normas generales sobre información a entregar al público acerca del asegurador y corredor de seguros, y; normas sobre promoción, publicidad
} 
El Código de Comercio chileno, en consecuencia, reguló el seguro de forma supletoria y a modo de restricción, en ciertos aspectos, de la autonomía privada. La mirada del legislador, en cualquier caso, siempre fue del lado del asegurador a nuestro entender. Sánchez Calero, en el derecho comparado, opina que esa restricción a la autonomía de la voluntad, y en lo que es válida esta afirmación para el derecho chileno, debería resultar hoy excepcional en materia de seguros, ya que ella se aleja del derecho que regula los contratos en general ${ }^{17}$. Tal y como aprecia Ghersi, ese es un esquema que hoy solo se reduce si enfrente contratan dos empresarios, grandes riesgos generalmente, donde el seguro forma parte de costos de circulación, distribución o comercialización de su propio producto o servicio, resumido tal escenario, a juicio de este autor, "bajo el epitafio contractual de contratos interempresarios"18.

En esta línea estaba, por ejemplo, el hoy derogado artículo 557 número $1^{\text {o }}$ del CCOM, y también en ella residían la gran mayoría de las condiciones generales o pólizas depositadas en la S.V.S. hasta hace un año. No es de extrañar que bajo esta misma lógica, las condiciones generales señaladas por el asegurador, podían incluso llevar a la liberación del asegurador de su obligación de indemnizar. Esta carga hoy tiene una nueva interpretación, la anterior había tornado simplemente en insostenible, abusiva e injusta. Hoy, además, sería ilegal.

El tráfico actual del derecho de los seguros, considera, tal y como expone Veiga que: “[E]n pocos contratos como en este se erosiona la bilateralidad contractual en la negociación del mismo a través de condicionados cerrados, impermeables, herméticos y no negociados. Condicionado que integra y contiene la extensión de las coberturas del riesgo o riesgos antiseleccionados (sic) previa, estadísticamente, por la entidad aseguradora. Delimitaciones que fijan, precisan, perimetran los límites causales del contrato de seguro, los que naturalizan pero también pueden desnaturalizar el contrato y funcionalidad real del seguro"19.

El contrato de seguro actual se ha vuelto mucho más complejo que la expresión simple y llana de la libertad contractual o la autonomía de la voluntad, ya que reconoce elementos técnicos y económicos en su creación y ejecución ${ }^{20}$. Baste solo pensar en que los seguros ope-

y oferta de seguros y de beneficios asociados a la contratación de pólizas de seguros. En ella se expresa que: "Cuando en la publicidad se promueva u ofrezca la contratación de una determinada cobertura de seguro, deberá especificarse el nombre de la póliza y cláusulas respectivas, con indicación del código de depósito en esta Superintendencia, el nombre de la o las compañías que otorgan la cobertura, y el nombre completo o razón social del corredor de seguros, en su caso. Asimismo, la publicidad de un seguro determinado que se efectúe a través de folletos o a través de páginas "web" de Internet, deberá contener adicionalmente, al menos, una descripción de las condiciones de la cobertura y exclusiones, monto y condiciones de pago de la prima y forma de aceptación y vigencia de la oferta del seguro". Todas las normas administrativas de SVS que se señalarán a continuación, están disponibles en www.svs.cl (fecha de consulta 19 de julio de 2014).

17 SÁnChez (2005) p. 61.

18 GHersi (2007) p. 169.

19 Veiga (2013) p. 642

20 Sobre este tema, Shavell (2000) pp. 166-179; Bataller, et al. (2007) pp. 18 y ss., exponen que: "El seguro responde al deseo de prevención contra un posible riesgo futuro que amenaza nuestra persona o nuestros bienes. Por tanto, podemos comenzar definiendo económicamente el seguro como aquella cobertura recíproca de una necesidad fortuita y estimable relativa a múltiples economías amenazadas de igual modo (...). La agrupación de riesgos homogéneos (principio de homogeneidad del riesgo) posibilita la obtención de una experiencia estadística y, partiendo de esta, un cálculo de probabilidades sobre el porcentaje de riesgos asegurados que a lo largo del año sufren un siniestro, sobre el porcentaje de las primas recaudadas en un año que deben destinarse a cubrir las obligaciones del asegurador y sobre el coste medio de cada siniestro. Todos ellos son datos necesarios para el cálculo de la prima de riesgo. Es, 
ran como una unidad de compensación de riesgos socialmente asumidos, que persigue legítimas utilidades para las compañías de seguros, únicamente concebibles mediante la contratación en masa. La superación de tales riesgos hoy, especialmente en los seguros privados, sigue estando representada por la prima que se paga. Ella ha devenido en un gasto periódico para el tomador, que puede y debe asumirlo, en algunos casos incluso, forzado por la propia ley.

Tener un seguro hoy es, para un empresario o particular por ejemplo, un costo más de producción o gasto, que aspira a ser fácil de llevar o pagar, y que la compañía de seguros, en cuanto a la posibilidad de indemnizar una vez ocurrido el siniestro, sujeta enteramente a su viabilidad económica.

El principal factor que aleja de la realidad del tráfico jurídico a las disposiciones originales del CCOM que venían del siglo XIX sobre el contrato de seguro es, a no dudarlo, el advenimiento durante el siglo XX de las condiciones generales de contratación. En el derecho comparado y nacional existen una gran cantidad de autores que han estudiado esta característica de la contratación moderna en materia de seguros y que nos enseñan sobre sus consecuencias en el contrato o su idea tradicional ${ }^{21}$. Así, todos coinciden en que la libre discusión de las cláusulas ya no concurre en el tráfico moderno de los contratos de seguros. Es más, no es extraño que estas cláusulas sean replicadas, en similares contratos, por diferentes empresas aseguradoras ante el mismo riesgo cubierto. La técnica actual es tan clara que autores como Veiga Copo sostienen que "sin condicionados no puede haber seguro"22.

El contenido del negocio propio de los contratos de seguros, terminó por imponer esta técnica de disposición estándar en su contenido y estructura, es esta nueva realidad del tráfico la que fuerza los cambios legislativos chilenos y que la industria aseguradora local deberá asimilar.

\section{MODIFICACIÓN DEL DEBER PRECONTRACTUAL DE INFORMACIÓN EN EL CONTRATO DE SEGURO, EN LA LPC CHILENA, POR LA LEY No 20.555 Y EN EL CCOM, LEY 20.667. ASPECTOS GENERALES}

Desde el mensaje del proyecto de reforma, enviado al Congreso por el Presidente de la República, se advierte la idea de reforzar en sus derechos a los consumidores asegurados ${ }^{23}$.

precisamente, en la homogeneidad del riesgo donde encontramos la división de los seguros en ramos y modalidades. Ramo es el concepto más amplio, que puede a su vez dividirse en modalidades de seguros. Así, por ejemplo, el ramo de incendio y eventos naturales comprende las modalidades de incendio, explosión, tempestad, eventos de la naturaleza distintos de las tempestades, energía nuclear y corrimientos de tierra. Sobre tales conceptos giran las garantías financieras durante el funcionamiento de la entidad aseguradora. No obstante, en la actualidad, algunos autores niegan que sea esencial la homogeneidad de la comunidad de riesgo. Argumentan que si aceptáramos la necesidad de este requisito, los grandes riesgos individualizados no obtendrían la calificación de seguro. Se afirma que la nueva ciencia económica ha prescindido de esta característica, lo que se ha trasladado a la ciencia jurídica. Ahora bien, sin negar la singularidad de determinados riesgos e incluso de algún mercado asegurador como el Lloyd's de Londres, se puede afirmar que tanto en la normativa de ordenación y supervisión vigente en Europa, como en la realidad del mercado asegurador, la homogeneidad del riesgo se encuentra presente entre las compañías aseguradoras".

21 Por citar algunos, Bruck (1930) pp. 25 y ss; Donati (1954) p. 110; Eichler (1966) pp. 60 y ss.; Uria (1962) pp. 10-21; Díez-Picazo (2007) p. 511; Beckmann (2009) p. 6; Sandoval (2004) p. 79; Solimando (2001) p. 26; Tapia y Valdivia (2002) p. 25.

22 Veiga (2008) p. 4.

23 Ley publicada en el D.O. el 5 de diciembre del 2011. La historia de la norma se encuentra disponible en: www.leychile.cl [fecha de consulta: 10 de septiembre de 2013]. 
Así, se señala ya en la página seis, cuarto párrafo de la historia de la ley, que: "Por tanto, consideramos indispensables fortalecer la protección del consumidor de servicios financieros, de telecomunicaciones y de transporte público de pasajeros, entre otros, a través de la dotación de mayores atribuciones y competencias al referido Servicio Nacional del Consumidor, perfeccionando la entrega de información y realizando estudios que reduzcan las asimetrías de información. Estas atribuciones servirán también en otros mercados regulados de similares características al financiero".

Demuestra preocupación singular el Poder Ejecutivo en su mensaje, por la alta cantidad de reclamos que se recibían en aquella época por el Servicio Nacional del Consumidor (en adelante SERNAC) en materia de seguros. Se sostiene en la página siete, segundo párrafo y siguientes de la historia de la norma, que: "Para formarse una idea cuantitativa de la situación que existe en las relaciones de consumo de ciertas actividades económicas, en los procedimientos relativos a la solución de desavenencias entre las partes, cabe señalar que durante el 2009 el Servicio Nacional del Consumidor recibió aproximadamente 328 mil consultas y 170 mil reclamos. De estos últimos, el 27\% correspondió al sector de servicios financieros y seguros, y el $26 \%$ al sector de telecomunicaciones. Es decir, mas (sic) de la mitad de los reclamos atendidos por dicho Servicio están concentrados en mercados regulados por leyes especiales.

En virtud de lo anterior, se pretende fortalecer la protección de personas que, particularmente en los ámbitos señalados, desarrollan operaciones susceptibles de ser resguardadas con los mismos principios y normas que protegen a los consumidores tradicionales..." Nótese que esta ley partió su tramitación antes del terremoto que sufrió el país el veintisiete de febrero de dos mil diez.

La historia de la reforma tiene su génesis, en consecuencia, en la preocupación de las autoridades chilenas ante el envejecimiento paulatino de las normas de seguros del Código decimonónico, y sus leyes anexas, las que no son suficientes para solucionar los crecientes problemas del tráfico jurídico de seguros.

Señala el mensaje que es necesario un cambio en las "leyes especiales destinadas a regular diversos subsectores de la industria financiera, tales como la ley General de Bancos, la ley de Sociedades Anónimas, la ley que rige a las Compañías de Seguros, la ley de cuentas corrientes bancarias y cheques, ley para operaciones de crédito de dinero, ley de impuestos de timbre y estampilla, o la ley que rige las administradoras de fondos de pensiones, entre otras". Agrega la autoridad que: "En algunas disposiciones de las leyes indicadas, no siempre se destacan las obligaciones de los prestadores de servicios y proveedores de bienes respecto a la obligación de informar eficazmente a los consumidores...”.

Para el Poder Ejecutivo chileno, resultaba prioritario "mejorar las condiciones para que los consumidores puedan acceder a la información sobre los productos y servicios que se les ofrecen, principalmente mejorando los canales de información a través de Internet"24; y con ello, "permitir al Servicio Nacional del Consumidor, mediante la correspondiente adecuación de su planta orgánica, la contratación de personal que desarrolle funciones relativas a mer-

${ }^{24}$ La historia de la norma se encuentra disponible en: www.leychile.cl [fecha de consulta: 10 de septiembre de 2013], página 9, donde se hace la descripción del Proyecto de ley 20.555, № 1. 
cados en los cuales las especialización y alto conocimiento técnico son requisitos ineludibles para desarrollar una adecuada protección" 25 .

La idea del legislador era replicar en Chile el sistema europeo, en cuanto crear una "Autoridad de Supervisión Bancaria” cuyo objetivo sería proteger el interés público, contribuyendo a la estabilidad del sistema financiero y entre cuyas atribuciones se encontraría la protección del consumidor de productos y servicios financieros.

Sus objetivos principales, de acuerdo a sus reglamentos, serían garantizar la correcta aplicación de la normativa correspondiente al sector financiero, a fin de preservar la estabilidad financiera, garantizar la confianza en el sistema en su conjunto y definir una protección suficiente para los consumidores de los servicios financieros.

Son fuentes de la actual normativa que afecta a la contratación de seguros en Chile, de acuerdo a la historia de la ley, tanto la legislación de Reino Unido como la de España, específicamente, la ley sobre protección y transparencia del consumidor financiero español ${ }^{26}$.

El seguro aparece comprendido, en estas fuentes en general, porque en ellos el contratante débil necesita de una protección más amplia. Estamos en estos casos frente a un tipo de contratación en la que el tomador no se representa dejar de contratar porque el seguro o la información entregada por él no es suficiente, simplemente contrata y lo hace no pocas veces sin medir las consecuencias de la opción que está tomando, y en innumerables oportunidades, sin saber por qué contrata un seguro y en qué condiciones.

Es importante, por lo tanto, que el contratante más débil en estas relaciones sepa por qué contrata y a qué se adhiere. Tal y como expresa Rehberg, su conocimiento debe ser claro y sin duda, en el que la información no debe ser demasiado extensa, es cierto, pero tampoco inexistente ${ }^{27}$.

El consumidor de seguros requiere que se le hable claro, que la redacción de las cláusulas sea entendible y no ambigua u oscura. Es por ello que debe ser guiado por el asegurador en sus declaraciones, asesorado, conforme al artículo $527 \mathrm{~N}^{\circ} 1$ del Código de Comercio. En razón del artículo 525 del Código de Comercio, además, el contratante tomador del seguro debe responder las preguntas del asegurador, pero recae en el asegurador la carga de la información al asegurado, en otras palabras, el asegurador debe preguntar muy bien en el nuevo esquema de la ley 20.667.

Si el asegurador no realiza de manera adecuada esa toma de información, de acuerdo a las nuevas reglas, pierde el derecho a reclamar por infracciones al deber de declaración del riesgo por parte del tomador del seguro y, conforme al artículo 529 número 1 del Código de Comercio, cuando el seguro fuere contratado en forma directa, sin intermediación de

\footnotetext{
25 La historia de la norma se encuentra disponible en: www.leychile.cl [fecha de consulta: 10 de septiembre de 2013], página 9, donde se hace la descripción del Proyecto de ley 20.555, No 5.

26 La historia de la norma se encuentra disponible en: www.leychile.cl [fecha de consulta: 10 de septiembre de 2013], página 114 y ss., sobre la Descripción del Proyecto de ley 20.555, No 5. En la página 134, del mismo Mensaje, se señala que: 'En Europa se creó la Autoridad Europea de Supervisión Bancaria, con el doble propósito de proteger al consumidor de productos y servicios financieros, y garantizar la estabilidad del sistema”. En la página 575, del Mensaje que nos ocupa, se expresa que: "Hace pocos días, fue publicada la ley sobre protección y transparencia del consumidor financiero español, la cual cumple con todos los estándares internacionales de la Unión Europea".

27 "Klar und durchschaubar, verständlich und widerspruchsfrei" REHBERG (2003) p. 224
} 
un corredor de seguros, debe: "prestar asesoría al asegurado, ofrecerle las coberturas más convenientes a sus necesidades e intereses, ilustrarlo sobre las condiciones del contrato y asistirlo durante toda la vigencia, modificación y renovación del contrato y al momento del siniestro. Cuando el seguro se contrate en esta forma, el asegurador será responsable de las infracciones, errores y omisiones cometidos y de los perjuicios causados a los asegurados".

La importancia de esta norma la deja de manifiesto Osvaldo Contreras al señalar: "Sirvió de acicate para legislar en este sentido, el muy completo sistema que contempla respecto de este tema, la nueva ley alemana sobre el contrato de seguro, que entró en vigencia el 1 de enero de 2008. Como consecuencia de esta nueva norma, el asegurado puede requerirle, no solo al corredor o a los agentes del asegurador, sino a este mismo, la asistencia que requiera en conexión con los seguros que desea contratar o que haya contratado, en la forma y oportunidad que los Artículos 529 1) del C.Com y el art. 57 del D.F.L. No 251"28.

La ley 20.555 buscaba resolver en consecuencia, entre otros, problemas de asimetría de información que se observan entre los distintos proveedores de servicios y sus destinatarios o consumidores, todo dentro del marco de la ley 19.496 sobre protección de consumidores.

Gracias a esta primera mirada general sobre los seguros y esta nueva normativa, que hasta aquí hemos realizado, parece claro que se trata de una legislación que llena un vacío del sistema jurídico chileno en torno a los seguros, sin perjuicio de que ya los propios aseguradores habían intentado avanzar en este camino de manera autónoma. En efecto, las aseguradoras nacionales, que se encuentran afiliadas a la Asociación de Aseguradores de Chile (en adelante AACh), decidieron en el año dos mil dos otorgarse un sistema de control y aplicación de buenas prácticas. Surgió así el Código de Autorregulación y un Compendio de Buenas Prácticas Corporativas. Su verificación por parte de los asociados es vigilado por un Consejo de Autorregulación.

Sin embargo, no fue este el único paso dado ya que en el año dos mil siete, el Consejo de Autorregulación, crea al Defensor del Asegurado: "Entidad encargada de velar por la correcta aplicación de las normas del Código de Buenas Prácticas Corporativas en aquellas situaciones específicas en que se produzca una controversia entre asegurado y aseguradora" 29 . En un intento por darse reglas, y en un esfuerzo por alinearse con las tendencias internacionales en materia de contratación de seguros, la industria en su conjunto, durante el año dos mil diez, decidió que las decisiones del Consejo de Autorregulación y las del Defensor del Asegurado, serían obligatorias y vinculantes para las todas las compañías de seguros asociadas a la Asociación de Aseguradores de Chile.

No obstante, y como la propia exposición de motivos de la ley 20.555 constata, según hemos explicado, a ojos del legislador chileno, estos esfuerzos fueron claramente insuficientes. Es consecuencia, por lo tanto, de un análisis de las autoridades chilenas, específicamente del Ministerio de Economía, Fomento y Turismo, sobre los problemas de asimetría de información y los reclamos ante redacciones imprecisas de cláusulas propias de contratos de seguros, tanto generales como particulares, que surge el nuevo marco legal que nos ocupa. Así

28 Contreras (2014) p. 266.

29 Para una explicación en la materia, vid. Claude (2012) pp. 56-59. 
queda específicamente señalado desde el mensaje con que se inicia la tramitación legislativa de la ley ${ }^{30}$.

El hecho de que estas normas nuevas, que rigen el contrato de seguro de ahora en adelante en Chile, se inserten en la ley del consumidor, hace desde ya pensar en una serie de consecuencias importantes.

A. La posible influencia de la legislación de los EE.UU. en la ley 20.555, QUE MODIFICÓ LA LEY DE PROTECCIÓN DE CONSUMIDORES EN EL DEBER PRECONTRACTUAL DE INFORMACIÓN

Una de las posibles influencias de la nueva legislación chilena de seguros pudiera haber sido la legislación norteamericana. Esto porque se desprende de la historia de la norma, en palabras del diputado señor Arenas, que lo que se busca es una "especie de Sernac Financiero Norteamericano" 31 .

Nos preguntamos ¿Es posible homologar el esquema de EE.UU. al que ahora rige en Chile en estas materias? Veamos.

La entidad referida por el diputado Arenas en la historia de la norma, es la "Consumer Financial Protection Bureau"32. Dicha institución da aplicación a una serie de normas, que en su página web se indican, y que forman parte del Code of Laws of the United States of America (U.S. Code) ${ }^{33}$. Esta regulación, da lineamientos generales en materia de protección del consumidor financiero y no señala en ninguna de sus partes qué se debe entender como producto financiero ${ }^{34}$. Además, se observan ciertas indicaciones de la Comisión Federal de Comercio para los consumidores en materia de Seguro de Crédito ${ }^{35}$.

30 Página 9 y ss., Descripción del Proyecto de ley 20.555, No 5 . La historia de la norma se encuentra disponible en: www.leychile.cl [fecha de consulta: 10 de julio de 2014].

31 La historia de la norma se encuentra disponible en: www.leychile.cl [fecha de consulta: 10 de septiembre de 2013], la cita al diputado Arenas aparece en la página 554 de la historia de la norma.

32 Véase en http://www.consumerfinance.gov/ [fecha de consulta: 10 de julio de 2014].

33 Véase en http://www.consumerfinance.gov/regulations/ [fecha de consulta: 10 de julio de 2014].

34 La Federal Deposit Insurance Corporation (véase en http://www.fdic.gov/regulations/laws/rules/6500-200. html\#fdic6500103) [fecha de consulta: 10 de julio de 2014]. Se refiere a la determinación de la carga financiera y en ella hace alusión al seguro: $\$ 106$. Determinación de la carga financiera(A). Salvo disposición en contrario en este apartado, el importe de la carga financiera en relación con una transacción de crédito al consumo se determinará como la suma de todos los cargos, pagados directa o indirectamente por el persona a la que el crédito se extiende y graven directa o indirectamente por el acreedor como un incidente para el otorgamiento de crédito. La carga financiera total no incluye los cargos de un tipo a pagar en una transacción en efectivo comparable. La carga financiera total no se incluyen los honorarios y las cantidades impuestas por agentes terceros de cierre (incluidos los agentes de liquidación, abogados y compañías de custodia y cargo) si el acreedor no requiere la imposición de los cargos o de los servicios prestados y no retiene los cargos. Ejemplos de gastos que se incluyen en las cargas financieras incluyen cualquiera de los siguientes tipos de cargos que sean aplicables:(1) Los intereses, la diferencia de precio en tiempo, y cualquier cantidad pagadera en virtud de un punto, descuento u otro sistema de cargos adicionales.(2) Servicio o llevar carga. (3) Préstamo de cuota, prima por descubrimiento, o un cargo similar. (4) Tasa por un informe de investigación o de crédito. (5) primas u otras cargas de cualquier garantía o seguro para proteger al acreedor contra el impago del deudor o pérdida de crédito. (6)Prestatario pagados los honorarios del corredor de hipoteca, incluyendo los honorarios pagados directamente al corredor o al prestamista (para su entrega al agente) si dichas tasas se pagan en efectivo o financiado.

35 Véase en http://www.consumidor.ftc.gov/articulos/s0110-seguro-de-credito [fecha de consulta: 10 de julio de 2014]. 
Queda en evidencia en el sistema de EE.UU. la falta de una regulación más orgánica y detallada a nivel federal sobre protección de los consumidores, específicamente del financiero, cuestión que resulta del todo lógica, en cualquier caso, considerando la estructura y organización del ordenamiento jurídico de los Estados Unidos de Norteamérica. En consecuencia, es posible emprender un estudio de la normativa relativa al consumo a nivel estatal norteamericano, pero a poco andar se torna una tarea muy ardua ${ }^{36}$.

Si uno revisa las distintas legislaciones al interior de EE.UU., es posible afirmar que, de la revisión del Common Law en este país, la legislación chilena, tanto en su institucionalidad como en la legislación aplicable a casos particulares, no tiene su fuente en la normativa de EE.UU. Es más, son sustancialmente distintas estas regulaciones y sus soluciones a las existentes tanto en Chile como a las investigadas en Europa.

Es consecuencia, estimamos que de la historia legislativa de la ley $\mathrm{N}^{\circ} 20.555$ no es posible concluir de un modo categórico, que la normativa de derecho del consumidor de Estados Unidos sea efectivamente fuente de la regulación nacional en la materia.

\section{B. LA LEGISLACiÓN EUROPEA TENIDA EN CUENTA EN EL CAMBIO LEGISLATIVO CHILENO}

DEL DEBER PRECONTRACTUAL DE INFORMACIÓN

Tal y como refieren las fuentes de la historia de la ley 20.555, en el mes de julio de 2012, la Comisión Europea propuso una nueva legislación para aumentar la protección de los consumidores de servicios financieros, esto debido a que la "crisis financiera se ha convertido en una crisis de confianza de los consumidores. La falta de transparencia, una escasa conciencia de los riesgos y una mala gestión de los conflictos de intereses ha supuesto que se han devenido una y otra vez a los consumidores de toda la UE productos de inversión y de seguros que no les convenían. Los consumidores han perdido la confianza en el sector financiero" ${ }^{37}$.

La legislación europea considera que, en general, la política en materia de servicios financieros incluye tres sectores principales: a) el sistema bancario; b) los seguros y, c) los valores mobiliarios. Más allá de la reglamentación destinada a los operadores y a los inversores (bancos, seguros, valores mobiliario), la Unión se propone, asimismo, proteger aún más a los consumidores en ámbitos específicos como los servicios financieros al por menor ${ }^{38}$.

\footnotetext{
36 Las siguientes legislaciones internas contienen los aspectos relevantes que permiten aproximarnos a la determinación de la relación entre el seguro y el producto financiero en el sistema de los Estados Unidos y en los que alguna referencia existe: Montana Code; Kansas Code; Texas Finance Code; Statute Florida; General Laws of Massachusetts; Code of Virginia; Michigan Consumer Protection Act; Consumer Protection in New Hampshire; Maine Consumer Credit Code; Lousiana Insurance Code; Missouri Electronic Code of Federal Regulations, Title 12: Banks and Banking; Oklahoma Uniform Consumer Credit Code e Indiana Uniform Consumer Credit Code.

37 Disponible en http://europa.eu/rapid/press-releade_IP-12-736_es.htm[fecha de consulta: 10 de julio de 2014]. De acuerdo a esta información, el paquete se compone de tres propuestas legislativas: una propuesta de Reglamento sobre los documentos informativos clave en relación con los productos preempaquetados de inversión minorista (PPIM), una revisión de la Directiva sobre la mediación de seguros (DMS) y una propuesta de refuerzo de la protección de quienes compren fondos de inversión, que se rigen actualmente por la Directa sobre los organismos de inversión colectiva en valores mobiliarios (OICVM).

38 Disponible en http://europa.eu/legislation_summaries/internal_market/single_market_services/financial.htm y http://europa.eu/legislation_summaries/internal_market/index_es.htm (fecha de consulta 3 de octubre de 2013).
} 
En nuestro concepto, cobra especial importancia para analizar la legislación chilena surgida de la reforma al mercado de los seguros, la Directiva 2002/65/CE del Parlamento Europeo y el Consejo, relativa a la comercialización a distancia de servicios financieros destinados a los consumidores ${ }^{39}$. El ámbito de aplicación de esa Directiva se aplica a los servicios financieros al por menor (servicios bancario, de seguros, de pago y de inversión, incluidos los fondos de pensiones) negociados a distancia (por ejemplo, por teléfono, fax o Internet), es decir, por cualquier medio, sin que exista una presencia física simultánea de las partes del contrato ${ }^{40}$.

\section{i. La Directiva 2002/65/CE del Parlamento Europeo y el Consejo en la génesis de la ley 20.555 y el deber precontractual de información}

Nos parece bastante más decisiva la influencia de la legislación europea, en general, en la historia de la ley 20.555. En efecto, un importante papel cumple la Directiva 2002/65/CE del Parlamento Europeo y el Consejo, de 3 de septiembre de 2002, relativa a la comercialización a distancia de servicios financieros destinados a los consumidores, ya que esta a aplica a los seguros, negociados a distancia o por cualquier medio.

Establece un sistema riguroso en cuanto a la entrega de información que deben recibir los consumidores de seguros antes de la celebración del contrato y regula, muy especialmente, el derecho de desistimiento.

En el artículo dos, en las definiciones, se señala que: "A efectos de la presente Directiva, se entenderá por: "servicio financiero": todo servicio bancario, de crédito, de seguros, de jubilación personal, de inversión o de pago".

¿Qué quiere decir esto para el caso chileno? que de acuerdo a este estudio de fuentes, el seguro es un producto financiero y así fue pensado por el legislador desde un comienzo, desde el modelo que tuvo en cuenta para legislar. Esta afirmación se corrobora, además, porque como puede advertirse, esta es precisamente la redacción que adopta la ley del consumidor 19.496 en el artículo 17 B, en su texto definitivo y publicado: "Los contratos de adhesión de servicios crediticios, de seguros y, en general, de cualquier producto financiero, elaborados por bancos e instituciones financieras o por sociedades de apoyo a su giro, establecimientos comerciales, compañías de seguros, cajas de compensación, cooperativas de ahorro y crédito, y toda persona natural o jurídica proveedora de dichos servicios o productos...”.

La regulación de la Directiva 2002/65/CE presenta elementos que claramente buscan la protección del consumidor de seguros. Se prevé la existencia de un derecho de desistimiento en las directivas sobre el seguro de vida y de crédito al consumo. No cabe la menor

\footnotetext{
39 Así en España, la Ley 22/2007, de 11 de julio, sobre comercialización a distancia de servicios financieros destinados a los consumidores, fija un plazo general de catorce días naturales para desistir del contrato, si bien, tratándose de contratos relacionados con seguros de vida, el plazo será de treinta días naturales; y empezará, como regla, a correr desde el día de la celebración del contrato, salvo en relación con los seguros de vida, en que el plazo comenzará cuando se informe al consumidor de que el contrato ha sido celebrado (artículo 10.1). Este precepto trae causa del artículo 6o (derecho de rescisión) de la Directiva 2202/65/CE del Parlamento Europeo y del Consejo, de 23 de septiembre de 2002. Beluche (2009) p. 71.

40 Disponible en http://europa.eu/legislation_summaries/internal_market/single_market_services/financial. htm[fecha de consulta: 10 de julio de 2014].
} 
duda de que es posible detectar, como técnicas de protección del contratante débil en materia de seguros, la puntual información precontractual o el derecho de desistimiento ${ }^{41}$. Tal y como señala De la Maza, a propósito de la influencia de esta Directiva 2002/65/CE, la mayoría de estos servicios financieros quedarían cubiertos por la ley $\mathrm{N}^{\circ} 20.555$ en Chile ${ }^{42}$.

La Directiva reemplazó a la anterior del año 1987 y adoptó un sistema más amplio y completo de protección del consumidor en relación con los contratos de crédito ${ }^{43}$. El propósito general de la directiva es garantizar la libertad de elección de los consumidores y generar la confianza necesaria en la contratación a distancia. No es sino reflejo del dinámico tráfico actual, el masificado uso de internet, el que se presenta como un canal de información, distribución y contratación de seguros. En qué insiste claramente la directiva que nos ocupa, fuente de la actual legislación chilena, en que no puede haber nada en el contrato que no se haya consentido al momento de contratar. Así, expresa que se comunicará al consumidor la información de manera clara y comprensible, por cualquier medio que se adapte a la técnica de comunicación a distancia utilizada, respetando debidamente, en particular, los principios de buena fe en las transacciones comerciales y los principios que regulan la protección de las personas.

La Directiva 2002/65/CE establece, desde su considerando 21, que ella supone exigencias destinadas a conseguir un nivel adecuado de información del consumidor, tanto antes de la celebración del contrato como después de esta.

El consumidor, antes de la celebración de un contrato, debe recibir las informaciones previas necesarias para poder apreciar convenientemente el servicio financiero que se le propone y, en consecuencia, realizar su elección con conocimiento de causa. El proveedor debe especificar por cuánto tiempo es válida su oferta.

La información y su estándar es de carácter general y por ello aplicable a los servicios financieros de todo tipo, incluidos los seguros, no obstante las propias peculiaridades que estos tienen.

En el caso de comunicación a través de telefonía vocal, resulta interesante la forma en que debiera contratarse:

a) al comienzo de toda conversación con el consumidor se indicará claramente la identidad del proveedor y el fin comercial de la llamada iniciada por el proveedor;

b) previa aceptación expresa del consumidor, solo deberá suministrarse la información siguiente:

- la identidad de la persona en contacto con el consumidor y su vínculo con el proveedor,

- una descripción de las características principales del servicio financiero,

- precio total que deba pagar el consumidor al proveedor del servicio financiero, incluidos todos los impuestos pagados a través del proveedor o, cuando no se pue-

\footnotetext{
41 Sobre la implementación en España de esta directiva: Pérez de Madrid (2012) pp. 427 y ss. Munar Bernat (2002) pp. 1189 y ss.

42 De la Maza (2013) p. 383

43 Stuyck Jules (2012) p. 168. En la misma obra, Domínguez (2012) pp. 214 y ss.
} 
da indicar un precio exacto, la base de cálculo que permita al consumidor comprobar el precio,

- indicación de que puedan existir otros impuestos o gastos que no se paguen a través del proveedor o que no los facture él mismo,

- la existencia o inexistencia de un derecho de rescisión y, de existir ese derecho, su duración y las condiciones para ejercerlo, incluida información relativa al importe que pueda exigirse que pague el consumidor.

El proveedor informará al consumidor acerca de la existencia de información adicional disponible previa petición y del tipo de información en cuestión.

La información sobre las obligaciones contractuales, que deberá comunicarse al consumidor durante la fase precontractual, deberá ser conforme a las obligaciones contractuales que resulten de la legislación normalmente aplicable al contrato si este se celebrara.

En el artículo 5 de la Directiva 2002/65/CE, se establece que el proveedor comunicará al consumidor todas las condiciones contractuales en soporte de papel u otro soporte duradero accesible al consumidor y puesto a su disposición con la suficiente antelación antes de que el consumidor asuma obligaciones mediante cualquier contrato a distancia u oferta.

En cualquier momento durante la relación contractual, el consumidor tendrá derecho a obtener, si así lo solicita, las condiciones contractuales en soporte de papel. Es más, si el consumidor ejercita su derecho a rescisión el proveedor no podrá exigir pago alguno del consumidor, a menos que pueda demostrar que el consumidor ha sido debidamente informado del importe adeudado.

En relación a la carga de la prueba, los Estados miembros podrán disponer que la carga de la prueba del cumplimiento de las obligaciones que incumban al proveedor en materia de información del consumidor, así como del consentimiento del consumidor para la celebración del contrato y, cuando proceda, para su ejecución, pueda recaer en el proveedor, conforme lo dispone el artículo 15 de la Directiva 2002/65/CE. Es más, conforme al artículo 16 del mismo cuerpo legal, tendrá la consideración de cláusula abusiva, con arreglo a lo dispuesto en la Directiva 93/13/CEE del Consejo, de 5 de abril de 1993, sobre las cláusulas abusivas en los contratos celebrados con consumidores, toda cláusula contractual por la que se establezca que la carga de la prueba del cumplimiento, por parte del proveedor, de la totalidad o de parte de las obligaciones que le incumben en virtud de la presente Directiva, recaiga en el consumidor.

Como puede apreciarse, las directivas señalan al derecho interno de los estados que ellos deben garantizar la aplicación de un estándar mínimo de protección ${ }^{44}$.

Lo que se pretende, a nuestro juicio, es lograr un viejo principio y anhelo de la contratación, que ha matizado siempre el pacta sunt servanda, y es que la propia validez y cumplimiento de los contratos no puede dejarse al arbitrio del predisponente de su clausulado ${ }^{45}$.

\footnotetext{
44 Fallon y FrancQ (2000) p. 156

45 Piénsese en el artículo 1566 del Código civil chileno: "Art. 1566. No pudiendo aplicarse ninguna de las reglas precedentes de interpretación, se interpretarán las cláusulas ambiguas a favor del deudor.

Pero las cláusulas ambiguas que hayan sido extendidas o dictadas por una de las partes, sea acreedora o deudora, se interpretarán contra ella, siempre que la ambigüedad provenga de la falta de una explicación que haya debido darse por ella.
} 
En definitiva, la idea de la directiva es que el consumidor a distancia sea equiparado al consumidor presencial y que contrata directamente un seguro ${ }^{46}$.

\section{ii. La reforma inglesa: Financial Services Act y su influencia en la reforma chilena de seguros y el deber precontractual de información.}

La reforma a la legislación bancaria del Reino Unido efectivamente comenzó a regir el 1 de abril de 2013, sin embargo su estudio y contenido fue discutido por años y se encontraba disponible para su conocimiento en internet, como tendremos oportunidad de analizar. Es la "Financial Services Act" que creó la nueva Autoridad de Supervisión en materia de Servicios Financieros, que incluye, expresa y específicamente, la supervisión de las Compañías de Seguros, también dentro de la protección de los consumidores.

El paso dado en la legislación inglesa es significativo, ya que supone abandonar aquella tendencia propia del sistema inglés a mirar más a la apariencia objetiva de un acuerdo ya producido y acercarse al sistema continental en la formación del consentimiento de seguros.

En la reglamentación de consumidores de crédito, anterior a la reforma de 2013 en Inglaterra, se regulaban los préstamos de dinero y todas las actividades coligadas al otorgamiento de tales créditos. Eran alcanzadas por esta regulación las cobranzas y la gestión de la misma; los préstamos de consumo; las tarjetas de crédito; y en general, todas las ventas de bienes y servicios a crédito. Cualquiera de estas actividades debía contar con la autorización del Office of Fair Trading (en adelante, OFT) ${ }^{47}$.

Lo destacable de la normativa, que dejó de estar vigente en Reino Unido en abril de 2013, pero que influyó definitivamente en la legislación dictada en Chile, es que se impone a todo intermediario del sistema de créditos una pormenorizada cantidad de información previa al contrato.

En efecto, la sección 55 A de la Consumer Credit Act (en adelante Ley de Crédito al Consumo) exigía a los acreedores (o intermediarios que actúen en su nombre) proporcionar

46 De ahí que el consumidor cuente con herramientas para protegerse de agresivas técnicas de marketing que lo inciten a firmar rápidamente un clausulado general que comprometa sus derechos irrenunciables como consumidor. El objetivo de la directiva es precisar que, como sucede en la contratación de seguros, si el contrato supone que el iter de formación del consentimiento está formado por un conjunto de actos sucesivos o una dinámica contractual de actos distanciados en el tiempo, esto no puede rebajar los derechos del consumidor en esa relación. El Considerando 16 señala que se aplica la directiva a la primera de una serie de operaciones sucesivas o distintas del mismo tipo, escalonadas en el tiempo, y que puede considerarse que forman un todo, tanto si esta operación o esta serie de operaciones son objeto de un único contrato o de diferentes contratos sucesivos. De esta manera, el acuerdo inicial sería la formación del consentimiento en el momento en que se contrata el seguro en la compañía o ante el corredor. Añadir, con posterioridad a ese momento, nuevos elementos al acuerdo inicial son operaciones sucesivas de distinta naturaleza y a las que no cabe aplicar por extensión consentimientos de la operación inicial. Interés representa también conocer quién es consumidor y quién proveedor de acuerdo a la Directiva de un producto como el seguro. La Directiva debe aplicarse también cuando una de las etapas de la comercialización se desarrolle con la participación de un intermediario, con independencia de su régimen jurídico. Es necesario precisar que para el legislador comunitario no es consumidor el destinatario final de los bienes o servicios, sino aquel que actúa fuera de su marco de actuación profesional o comercial, pudiendo los estados en su legislación particular comprender a las personas físicas o jurídicas.

47 Disponible en http://www.oft.gov.uk/;jsessionid=FC66F46411B816C0CD480F141D3E3097 (fecha de consulta 3 de octubre de 2013). La OFT contaba con el capítulo 8 y el capítulo 3 donde se podía analizar una auténtica guía de préstamos irresponsables lo que cubría temas relacionados con la solvencia y rentabilidad. 
una explicación adecuada anterior a que el contrato de préstamo se realizara. Esta Sección 55A se introdujo a través de la Directiva (UE) Reglamento de Crédito al Consumidor de 2010. El propósito era permitir al consumidor evaluar si el acuerdo se adaptaba a sus necesidades y su situación financiera. Se requería de esta manera entregar por el otorgante del crédito las características del mismo, buscando estandarizar la información.

Se debía facilitar al consumidor el monto real que periódicamente pagaría el deudor de ese futuro crédito y un conjunto de características que pudieran tener un efecto adverso y significativo en la manera que el obligado cumpliría con sus obligaciones. Había, en definitiva, la obligación de informar al consumidor las consecuencias que acarrearía no cumplir los pagos, destacando los procedimientos a seguir en tal caso, como asimismo, la posibilidad de desistirse de los créditos y las posibilidades de ejercer tal derecho ${ }^{48}$.

Siempre se le daba la posibilidad al consumidor de poder cuestionar, en cualquier momento, el tipo de información que se le entrega y solicitar un detalle mayor. En fin, se regulaba expresamente la entrega de información verbal y por escrito a través de hojas informativas ${ }^{49}$.

Estas mismas normas prohibían, por considerarlas prácticas abusivas, la modificación unilateral de los contratos, en especial en aquellos casos en los que se alteraban las comisiones, el capital a pagar no notificado oportunamente, como también alteraciones unilaterales de las tasas de interés o el capital pactado en el préstamo o notificaciones no realizadas de cesiones de derechos de la calidad de acreedor ${ }^{50}$.

Existía siempre la posibilidad de modificar el contrato de consumo, de hecho el acreedor podía reservar esta facultad, pero para ello debía siempre notificar tal modificación, y por escrito, si se trataba de modificaciones asociadas a los pagos del deudor.

Se le daba expresa facultad a los tribunales para cambiar los contratos que consideren abusivos en sus cláusulas, ya sea todo o parte del mismo o en una cláusula en específico. Procesalmente, conforme a la norma 140 de la Ley de Crédito al Consumo, una vez que se presentaba una demanda por cláusulas abusivas, la carga de la prueba recaía en el acreedor, no en el consumidor ${ }^{51}$.

La nueva regulación vigente desde el primero de abril de 2013 en Inglaterra, no necesariamente significa mayores rigideces en la información que ya se entregaba, sino que se traspasa el control de toda ella a un solo organismo regulador en la búsqueda de evitar duplicidades de competencia, disminuir los costos de fiscalización y atender de mejor forma las quejas de los consumidores y usuarios. La Autoridad de Conducta Financiera se hizo cargo de la regulación del crédito al consumo de la OFT a partir del 1 de abril de 2014,

\footnotetext{
48 Disponible en http://www.oft.gov.uk/about-the-oft/legal-powers/legal/cca/Precontractinformation\#. Uk24h9IagpU (fecha de consulta 3 de octubre de 2013).

49 Disponible en http://www.oft.gov.uk/about-the-oft/legal-powers/legal/cca/CCA2006/information/\#.Uk3C7dIagpU (fecha de consulta 3 de octubre de 2013).

50 Para un amplio registro de casos, http:/www.oft.gov.uk/about-the-oft/legal-powers/legal/cca/CCA2006/ unfair/unfair-rel-full/\#.Uk3DsdIagpU (fecha de consulta 3 de octubre de 2013).

51 Disponible en http://www.oft.gov.uk/about-the-oft/legal-powers/legal/cca/Postcontractinfo\#.Uk3F2NIagpU (fecha de consulta 3 de octubre de 2013).
} 
con la misión de desterrar malas prácticas y sacar empresas con mal comportamiento, promoviendo la competencia en el mercado del consumo ${ }^{52}$.

Todas las empresas que actualmente tienen una licencia de crédito al consumo (en adelante CCL), solo podrán operar bajo su actual CCL hasta el 31 de marzo de 2014. Todas las licencias para otorgar crédito al consumo expiraron en la citada fecha, a la medianoche, y si no se renovaron no podrán continuar con sus actividades de crédito. La nueva autoridad es la The Financial Conduct Authority (en adelante FCA), la que desde septiembre de 2013, otorga permisos provisionales para llevar a cabo las actividades reguladas por ella a partir del 1 de abril de 2014.

Es absolutamente notorio que gran parte de los artículos de la ley 20.555 se basan en la experiencia inglesa señalada, y es posible, a nuestro juicio, hacer paralelos entre la legislación chilena y la inglesa. Es más, gran parte de su contenido está basado en la legislación europea, específicamente la Directiva 2002/65/CE. Así, hoy tiene derecho el consumidor a recibir información del costo total del contrato (Art. $17 \mathrm{~B}$ letra a) LPC) y las condiciones objetivas establecidas por el proveedor (Art. 17 B letra b) LPC). Tratándose de contratos de adhesión, como los seguros, el proveedor debe informar el cobro de los bienes y servicios prestados (Art. 17 B letra a) LPC). El Art. 17 B letra b) LPC, establece un mínimo que deberán especificar estos contratos, haciendo símiles en su encabezado de artículo los seguros y los productos financieros. Asimismo, el Art. 17 E LPC otorga la facultar de solicitar la nulidad de las cláusulas que infrinjan la anterior disposición. El Art. 17 C LPC es igualmente aplicable a los seguros, ya que establece la necesidad de contener, al inicio del contrato, una hoja con un resumen estandarizado de sus principales cláusulas ${ }^{53}$. El Art. 17 D LPC nuevamente hace alusión al Derecho a información por parte del asegurado. El Art. 17 F LPC establece la prohibición de enviar contratos representativos no solicitados, por último, la prohibición de ventas atadas es también aplicable a los contratos de seguros (Art. 17 H LPC).

iii. La ley española de seguros como fuente del deber de información precontractual en la ley 20.667

Obviamente que por compartirse la misma lengua, resulta notoria la influencia de la legislación española en la tramitación de las leyes 20.555 y 20.667. No son pocas las disposiciones tomadas casi literalmente y sería ocioso el tratarlas una por una. Bastará, simplemente, dar una idea general sobre la Exposición de Motivos de la Ley 30/1995, de 8 de noviembre de ese año, de ordenación y supervisión de los seguros privados. Su función era: "tutelar a favor de los asegurados y beneficiarios amparados por un contrato de seguro (...) la protección al máximo de los intereses de los asegurados amparados por el seguro, no solo mediante el control administrativo genérico de las entidades aseguradoras, sino mediante la regulación de medidas específicas de tutela”. Este siempre ha sido el propósito de la legisla-

\footnotetext{
52 Sobre este particular, https://www.gov.uk/government/organisations/competition-and-markets-authority (fecha de consulta 3 de octubre de 2013).

53 Esto es necesario confrontarlo con la doctrina de las expectativas razonables ya que es una forma que tiene el proveedor de seguros para hacer sencilla la inteligencia de las pólizas y consecuencialmente, evitar una interpretación contra redactor por tratarse de cláusulas ambiguas o incomprensibles para un lego.
} 
ción mencionada que en la ley anterior 50/1980, de 8 de octubre, de contrato de seguro, se especificaba en su propio carácter, como normas que tenían una clara finalidad protectora ${ }^{54}$.

La legislación española, en general, se sustenta sobre un principio primordial a nuestro juicio: la mejor protección de los asegurados está íntimamente ligada a la correcta actividad del mercado, se opone a ello la asimetría de información precontractual que es más bien una falla de mercado que ha de ser corregida. Son precisamente estas desviaciones del mercado, que tienen su origen en la información precontractual deficiente, insuficiente o defectuosa, las que acarrean problemas de eficacia jurídica de los contratos.

Es decir, se ha de implantar un eficiente sistema de empresas aseguradoras independientes, concebidas de una fuerte solvencia patrimonial y financiera, que garanticen plenamente que las relaciones del mercado asegurador están presididas por la transparencia informativa, como corresponde a los mercados organizados donde se intercambian productos o servicios en masa, sometidos al cambio que en ellos operan las constantes innovaciones en la forma de entregar el contenido precontractual de un contrato.

Los deberes de buena fe propios de la interacción precontractual suponen ser precisos y claros en las condiciones de contratación de la ley española, tanto de condiciones generales de contratación como de protección de consumidores. Tal y como señala Veiga, "[C] obran de nuevo todo su protagonismo cuestiones tales como la antilselección del riesgo, el moral hazard y la verdadera actitud y comportamiento que frente al mismo atesora o mantiene el asegurado-tomador. Fijar el mejor y más óptimo nivel de cobertura y garantía, no solo depende de una buena técnica de seguro y antiselectiva de riesgos, sino también de la aptitud y comportamiento conductual frente al riesgo, ex ante y durante, del propio asegurado. Como de factores de asunción parcial y no total de ese riesgo por la propia aseguradora en aras a mantener y preservar un eficiente y activo incentivo de cooperación por parte del asegurado en aras a prevenir el propio daño, lo cual redundará o así debería serlo también el coste efectivo del propio aseguramiento" 55 .

iv. La reforma alemana de seguros de 2008 y su influencia en el deber de información precontractual en la ley 20.667

A nuestro juicio, lo que termina de cerrar el círculo de fuentes normativas en relación a la ley chilena y el nuevo deber de información y su alcance, es la Gesetz über den Versicherungsvertrag alemana de 2008, que rige desde 2008. Esto quedó expresamente reconocido en la historia de la ley 20.667, que modificó el Código de Comercio. En efecto, tal y como se expresó en el Congreso, hubo el expreso ánimo de seguir: “d) La reciente ley sobre contrato de seguro de Alemania, que entró en vigencia en enero de 2008 (...) ha introducido una norma similar a la que propone (art. 7), que va en directo beneficio y protección del asegurado y de la seriedad del sistema de seguros, encontrando unánime acogida en la

\footnotetext{
54 Se menciona el ordenamiento español expresamente en actas en el Congreso chileno durante la tramitación de la ley 20.555 en páginas: 34; 77; 133; 271; 297; 298; 395; 554; 555; 566; 574 y 575 para los más variados ámbitos. En el caso de la ley 20.667, páginas: 10; 59; 89; 90; 91; 99; 104; 106; 107; 108; 112; 118, también para los más variados aspectos. La historia de la norma se encuentra disponible en: www.leychile.cl [fecha de consulta: 10 de julio de 2014].

55 Veiga Copo (2013) pp. 642 y 678.
} 
doctrina mundial. Desde luego, cabe mencionar que ha sido acogida por la Comunidad Europea, que ha dictado una directiva haciendo aplicable dicho sistema de responsabilidades a toda la Unión" 56 .

¿Qué significa esto? Para la Gesetz über den Versicherungsvertrag perfeccionar un contrato de seguros es hacerlo de manera transparente y sencilla. Su $\$ 7$ Information des Versicherungsnehmers señala que la aseguradora deberá informar al tomador, por escrito, de sus condiciones de contratación, incluyendo los términos y condiciones generales de los seguros, con la suficiente antelación, y siempre antes de que el tomador dé su aceptación contractual. Esta información se facilitará de manera clara y comprensible, de acuerdo con el medio de comunicación empleado ${ }^{57}$.

$\mathrm{Si}$, a petición del futuro titular de la póliza, el contrato se celebra por teléfono o utilizando otro medio de comunicación que no permite que la información previa, que debe facilitarse por escrito antes de la aceptación contractual del asegurado, pueda ser entregada, ella deberá proveerse, sin demora innecesaria, después de que el contrato se perfeccione; lo mismo sucederá si el asegurado renuncia explícitamente al derecho a la información por una declaración aparte, por escrito, con anterioridad a la aceptación contractual del seguro.

El Ministerio Federal de Justicia dictó, en virtud de este mandato legal, un Verordnung über Informationspflichten bei Versicherungsverträgen o Reglamento sobre los requisitos de información para los contratos de $\operatorname{seguros}^{58}$.

${ }_{56}$ Así en la historia de la norma que se encuentra disponible en: www.leychile.cl [fecha de consulta: 18 de julio de 2014] pp. 96.

57 Disponible en http://www.gesetze-im-internet.de/vvg_2008/__.html [fecha de consulta: 19 de julio de 2014].

58 Este señala que la aseguradora debe tener siempre disponible la identidad legal de la aseguradora y sus filiales, el domicilio legal de la aseguradora y cualquier otra dirección geográfica que proceda para las relaciones del cliente entre el asegurador, su agente o de otro comercio, persona o empresa relacionada y el tomador del seguro, el caso de las personas jurídicas, sociedades de personas o grupos también el nombre de un representante autorizado. Asimismo, debe informar el principal negocio de la compañía de seguros; la información acerca de la existencia de fondos de garantía u otros mecanismos de indemnización no abarcados por la Directiva 94/19/CE del Parlamento Europeo y del Consejo, de 30 de mayo de 1994 sobre los regímenes de garantía de depósitos (DO L 135, p 5) y la Directiva 97/ 9/EC del Parlamento Europeo y del Consejo, de 3 de marzo de 1997, sobre indemnización de los inversores (DO L 84, p 22); Nombre y se especificará la dirección del Fondo de Garantía; las condiciones aplicables a las condiciones generales del contrato de seguro, incluyendo las regulaciones arancelarias; las características esenciales de la prestación del seguro, incluyendo información sobre la naturaleza, alcance y oportunidad de los beneficios por parte de la aseguradora; el precio total del seguro, incluyendo todos los impuestos y otros componentes del precio, donde las primas deben notificarse por separado, y si el contrato de seguro incluye una serie de contratos de seguros independientes, o si el precio exacto no se puede indicar, la información sobre la base de su cálculo que se tuvo en cuenta en el caso del tomador del seguro, con un comentario que permita determinar el precio; en su caso, los gastos adicionales, indicando el importe total a pagar, así como otros posibles impuestos, tasas o gastos que no se pagan a través de la aseguradora y las prestadas por él; especificar todos los costos incurridos por el Asegurado para el uso de los medios de comunicación a distancia, si se cobrará dicho costo adicional; las modalidades para el pago y cumplimiento, en particular, para el pago de las primas; la limitación de la duración de la validez de la información proporcionada, por ejemplo, la validez de las ofertas limitadas, especialmente en términos de precio; en su caso, una indicación de que los servicios financieros relativos a los instrumentos financieros que se encuentran sujetas a riesgos debido a sus características específicas, o de las operaciones que se llevarán a cabo con riesgos específicos o sus fluctuaciones de precios, ello porque el mercado financiero en algunas oportunidades, y en el pasado reciente alemán, reflejó cantidades que no fueron indicativos de los resultados futuros; las circunstancias y los riesgos deben ser descritos; la información sobre cómo se celebra el contrato, en particular, el inicio de la cobertura del seguro y los seguros, así como 
En el contrato de seguro alemán hay una carga o deber de información que debe ser realizada, siempre por escrito, previo a la celebración del contrato. Esto significa que debe ser, y por escrito, informado cualquier cambio en la información suministrada previamente, en cualquier seguro contratado. Estimamos que por expresa mención en la historia de la ley, debiera replicarse este mismo contenido en Chile.

\section{CONCLUSIONES}

1. Una clara consecuencia de que el contrato de seguro sea un producto financiero: irrenunciabilidad de derechos de información, establecidos a favor de los consumidores, en la etapa precontractual.

Luego de esta mirada a las fuentes reconocidas por el derecho chileno en las dos reformas legales al mercado de seguros, descartando a aquellas fuentes mediatas que no lo fueron, es posible desprender ciertas conclusiones.

La primera y más notoria consecuencia de que las nuevas normas sobre seguro estén en la LPC, dice relación con la norma del artículo 4 de la ley 19.496: "Los derechos establecidos por la presente ley son irrenunciables anticipadamente por los consumidores".

No queda ninguna duda que esta norma expresa una importante limitación a la autonomía de la voluntad y es una regla sobre la que descansa el principio de protección del contratante más débil. Tiene un claro carácter imperativo, y de alcance general, a todos aquellos derechos contemplados a favor de los consumidores en la LPC, en términos tales que de acuerdo a la doctrina chilena "se aboga por una interpretación extensa del contenido de esa norma"59.

Esta norma debe estar articulada e interpretada en armonía con los medios de defensa de los consumidores. En este sentido, por ejemplo, la norma sobre que el silencio no constituye aceptación en los actos de consumo, a que se refiere el art. $3 \mathrm{n}^{\circ} 1$ de la LPC, reviste el carácter de ser de orden público y, por lo tanto, cualquier pacto en contrario es nulo, de nulidad absoluta, ello gracias a la redacción propia del artículo 4 de la LPC. Esto no hace sino aplicable inmediatamente el artículo 1462 del Código Civil, parte primera, "Hay un objeto ilícito en todo lo que contraviene al derecho público chileno”. En consecuencia, cualquier

la duración del período durante el cual el solicitante debe adjuntar a la solicitud; la existencia o inexistencia de un derecho de desistimiento y las condiciones, modalidades de ejercicio, en particular, el nombre y dirección de la persona que puede ejercer la revocación del seguro, y los efectos de la abstinencia, incluyendo información sobre la cantidad, en caso de desistimiento del seguro por parte del tomador del seguro; información del tiempo de ejecución y, en su caso, la duración mínima del contrato; información sobre la terminación del contrato, en particular, a las condiciones de terminación contractuales, incluidas las sanciones; la jurisdicción competente; los idiomas en que se comunican los términos del contrato y se hace referencia en esta disposición a la información previa, y los idiomas en que el asegurador se compromete a conducir con el consentimiento del titular de la póliza para comunicarse durante la vigencia de este Acuerdo; los procedimientos y recursos posibles por interpretación del contrato y, en su caso, las condiciones de dicho acceso; se debe hacer constar expresamente que la posibilidad de que los asegurados puedan obtener reparación no se ve afectado; Nombre y dirección de la autoridad de supervisión competente y de la posibilidad de presentar reclamaciones a la autoridad; la forma de envío del contrato, incluidas todas las Condiciones Generales que hemos detallado. Disponible en http://www. gesetze-im-internet.de/vvg-infov/ [fecha de consulta: 19 de julio de 2014].

59 Así en Espada (2013) p. 195 
pacto en que se contravenga la norma sobre que el silencio no constituye aceptación en los actos de consumo es nulo y de ningún valor, conforme al artículo 10 del Código Civil ${ }^{60}$.

Sobre el particular, cabe recordar que los tribunales superiores han afirmado que esta solución de interpretación no importa el área del derecho en que se aplique, ya que: "[D] e la lectura del texto citado se desprende que esta es una norma prohibitiva, una de aquellas que impiden la realización del acto bajo cualquier circunstancia, a todo evento; frente a cuya infracción cabe aplicar lo dispuesto en el artículo 10 del Código Civil, esto es, que los actos que prohíbe la ley son nulos y de ningún valor, máxima sanción civil impuesta en nuestro ordenamiento jurídico, tendiente a proteger el actuar correcto, esto es ajustado a derecho, en la conducta de las partes que intervienen en los actos jurídicos de cualquier naturaleza, siendo al efecto irrelevante que se trate de materia civil, comercial, administrativa o de cualquier clase; por ser principios generales de derecho que en todo ámbito deberán respetarse" ${ }^{61}$. Es en este mismo sentido que el fallo Rol 12.355-11, de veinticuatro de abril de dos mil trece, de la Corte Suprema $^{62}$ (conocido como "fallo Cencosud") expresó que: "la normativa (se refiere a la LPC) contiene valoraciones de orden público que no pueden ser desatendidas, pues, conforme con el artículo $4^{\circ}$ de la Ley, los derechos que en ella se establecen no son renunciables anticipadamente por los consumidores" ${ }^{33}$.

2. La introducción del contrato de seguro en la ley 20.555, en el ámbito propio del consumo, ha generado importantes consecuencias para la regulación administrativa del contrato de seguro.

Efectivamente, supone adscribir a que el derecho del consumidor y tomador de seguros se mueve dentro de un orden de protección en el que la irrenunciabilidad de derechos de los consumidores es una regla indispensable para su eficacia. Con ello se busca obtener mejores condiciones para los consumidores tomadores de seguros, propias de un ámbito del derecho que se mueve con herramientas variadas que van desde las sanciones administrativas, pasando por las garantías o indemnizaciones de perjuicios en casos de incumplimientos y las nulidades parciales o totales de cláusulas aisladas o contratos íntegros.

La expresión "derechos" del artículo 4 de la LPC debe ser entendido en sentido amplio. Debe comprender la renuncia de cualquier facultad, por ejemplo, a través del silencio del aceptante o la renuncia de acciones para la protección de esos derechos o de cualquier interés legítimo protegido por la LPC. La prohibición de renuncia previa y la nulidad que ella lleva aparejada, no admite excepciones, ni siquiera cuando esté compensada con el otorgamiento de otras ventajas, como por ejemplo, mejores condiciones en el otorgamiento de un crédito o tasas preferentes o primas más baratas. Está en plena sintonía con ello la

\footnotetext{
60 "Art. 10. Los actos que prohíbe la ley son nulos y de ningún valor; salvo en cuanto designe expresamente otro efecto que el de nulidad para el caso de contravención".

61 "Superintendencia de Valores y Seguros contra BBVA Corredores de Bolsa" (2009) Corte de Apelaciones de Santiago, considerando $5^{\circ}$.

62 "Servicio Nacional del Consumidor con Cencosud Administradora de Tarjetas S.A." (2013), Corte Suprema. Pronunciada por la Primera Sala de la Corte Suprema, por los Ministros Sres. Nibaldo Segura P., Juan Araya E., Guillermo Silva G., Juan Fuentes B. y Abogado Integrante Sr. Jorge Baraona G, quien redactó este fallo.

63 Considerando segundo de la citada sentencia. El paréntesis es nuestro.
} 
Oficio Circular 7981, de dos mil, en lo relativo a la manifestación de la voluntad por parte del asegurado, señalando de manera perentoria que: “(...) No existe normativa administrativa, reglamentaria o legal, que permita sustituir la expresión inequívoca de la voluntad en la celebración del contrato de seguros por una ficta que se infiere pura y simplemente de su silencio, para la contratación de coberturas de seguro.

En la situación descrita, con relación al seguro, a los terceros usuarios la contratación entre una casa comercial u otra entidad y la aseguradora no le son oponibles, por lo cual la aceptación de la cobertura contratada en su favor debe efectuarse bajo su firma en documento escrito, separado e independiente, de tal forma que el asegurable exprese su voluntad inequívocamente".

Esta norma no hace más que ratificar la conformidad que debe tener la manifestación de la voluntad con el art. 3 letra a) de la ley de protección al consumidor, respecto a que el silencio no constituye aceptación en los actos de consumo y nos parece una norma premonitoria del actual concepto que se tiene del tipo de consentimiento a prestar por el consumidor tomador del seguro: escrito e inequívoco. Es por ello que la reciente Circular 2148, de 8 de abril de 2014, expresa que, a propósito de la "IV. ACEPTACIÓN DE LA OFERTA DE SEGUROS. Establecida la comunicación entre la compañía de seguros oferente, o intermediario, y el destinatario de la oferta, la aceptación de este último dará lugar a la emisión y envío de la póliza por parte de la compañía, debiendo proporcionarse además, en forma inmediata, un comprobante, código o número que respalde la contratación.

Únicamente podrá considerarse como aceptación la expresión de voluntad manifestada inequívocamente con la intención de celebrar el contrato propuesto, no pudiéndose interpretar o presumir el silencio en este sentido" ${ }^{64}$.

Un segundo paso, y que dejaremos para otra oportunidad en su desarrollo más profundo, por exceder los linderos del presente trabajo, es el relativo a que la sanción a estas normas es la nulidad. Creemos, en principio, que deberá interpretarse esta nulidad no como una manera de beneficiar al predisponente o asegurador, que podría ver en la nulidad del contrato una forma de liberarse de las obligaciones del mismo en desmedro del contratante débil, sino más bien, debiera interpretarse esta nulidad como en el derecho comparado ya se hace, esto es, imperativa solo para el proveedor ${ }^{65}$.

La técnica legislativa ya es conocida en este sentido, la imperatividad socorre en el resguardo de cláusulas establecidas en auxilio y salvaguarda de la autonomía de la voluntad y busca, en caso de contravención, la anulación de la cláusula correspondiente o del propio contrato celebrado. El objetivo que se persigue como deseable recuerda el viejo principio de conmutatividad que "mira como equivalentes" las prestaciones de las partes en el Código

\footnotetext{
64 "La compañía deberá entregar la póliza al contratante del seguro o al corredor que la hubiera intermediado dentro del plazo de cinco días hábiles desde la perfección del contrato. El corredor, a su vez, deberá entregar la póliza al asegurado dentro del plazo de cinco días hábiles siguientes a su recepción. Tratándose de seguros colectivos, la compañía o el corredor deberán entregar la póliza al asegurado, en el plazo antes indicado, en atención a lo señalado en el artículo 538 del Código de Comercio. Es responsabilidad de la compañía de seguros o del corredor, en su caso, acreditar la entrega de la póliza al asegurado". Todas las normas administrativas de SVS que se señalarán a continuación, están disponible en www.svs.cl (fecha de consulta 19 de julio de 2014).

65 PASQUau (2009) pp. 58-66.
} 
Civil, lo que por cierto no significa que lo sean. Se trata de compensar esas prestaciones bajo el viejo alero de la conmutatividad de las mismas, ese es su objetivo y económicamente corrige una falla de mercado como se ha tenido por varios autores la posibilidad de argumentar en el caso de los seguros ${ }^{66}$.

Los contratantes vuelven a ser iguales, pero porque la ley interviene. La ley 20.555 y 20.667 crean y obligan a los proveedores de servicios financieros, incluidas las compañías de seguros, a implementar en la práctica un amplio sistema de protección de los tomadores de esos seguros.

En concreto, la citada ley 20.555 agregó, al inciso segundo del artículo $3^{\circ}$ de la Ley 19.496, una serie de derechos en favor del "consumidor de productos o servicios financieros". Consecuencia de ello, hay quien podría verse inclinado a pensar que el ámbito de aplicación de la nueva normativa queda circunscrito a productos o servicios financieros únicamente, excluyendo los seguros. Descartamos esta posibilidad. A juzgar por la historia de la norma y sus referencias no es así, ya que se extiende a los seguros, los que aparecen considerados como tales desde la propia génesis de la ley. Tal y como afirma De la Maza: "Desde su dictación, el artículo $3^{\circ}$ de la ley $\mathrm{N}^{\circ} 19.496$ está dirigido a señalar los derechos de los consumidores en general, sin distinguir entre categorías o tipos de consumidores. Por consiguiente, en Chile nunca ha habido dudas respecto de que el usuario de productos financieros -si se cumplen los presupuestos legales- es para todos los efectos un consumidor" ${ }^{\prime \prime}$.

Es cierto, pero el consumidor de seguros no es igual al que compra en una multitienda, lo que ya se advierte como abordado en la comparación de derechos con otros ordenamientos. En Italia, por ejemplo, en relación a las normas que regulan el deber precontractual de declarar el riesgo, opina algún autor que esta carga informativa debe estructurarse sobre el terreno de la tutela de los consumidores de productos de seguros, que tienen algo entre manos que lo hace especiales: un riesgo que desean traspasar ${ }^{68}$. Sánchez Calero, en España, señala que si bien hay una manifestación del denominado derecho de consumo en el derecho de seguros, reflejado en la tendencia a la protección del denominado contratante débil, hay aspectos, que muestran una perspectiva distinta. Ello se manifiesta, a juicio del citado autor, en la percepción anticipada de la prima por parte del asegurador, ya que el asegurado cumple con la obligación de pagar el precio, y no recibe necesariamente la prestación del asegurador, sino cuando ocurre el riesgo amparado o siniestro. Se trata del elemento aleatorio de este contrato, que puede dar origen a un derecho en favor de personas distintas a los contratantes -o asegurados- como es el caso de los beneficiarios en los seguros de vida o los terceros perjudicados en los seguros de responsabilidad civil. En tal sentido, concluye Sánchez Calero que "parece manifiesto que la situación del asegurado no es igual que en otros supuestos de consumo de bienes o servicios" ${ }^{69}$. En el mismo sentido, otro autor expresa que: "en coherencia con la filosofía legal que inspira la ley de contrato de seguro, en desarrollo del principio constitucional

\footnotetext{
66 Díez-Picazo (2006) p. 14; Sánchez Calero (2001) pp. 96-97; Schulze (2006) p. 34.

67 De la MaZa (2013) p. 383.

68 BIN (1993) p. 729.

69 Sánchez Calero (1980) pp. 6-7.
} 
de tutela del consumidor, se debería haber limitado la protección legal, siguiendo el reflejo del derecho comparado (ley sueca), a los consumidores en sentido estricto, es decir, a los destinatarios finales del servicio en que consiste el seguro cuando se encuentran en situación de desigualdad económica, respecto del asegurador, o sea, en otras palabras, cuando no sean profesionales ni empresarios"70. No cabe duda que "la condición de consumidor del asegurado, exige la puesta en escena de la normativa prevista en nuestro Ordenamiento Jurídico para la defensa de los consumidores usuarios, y para los contratos celebrados con condiciones generales de la contratación al objeto de velar por el mantenimiento del equilibrio de las prestaciones entre las partes"71.

3. El derecho de información exigible actualmente en la contratación de seguros, excluidos los grandes riesgos, es anterior a la formación del consentimiento y este último debe respetar las reglas de la ley de protección de consumidores, antes que las normas propias deformación del consentimiento del Código de Comercio.

Ya desde el certificado de cobertura, que está íntimamente ligado con la entrega de la póliza del artículo 519 del CCOM y la prima del artículo 527 del mismo cuerpo legal, no puede desconocerse cobertura por parte de la aseguradora ni menos eximir su responsabilidad por faltarle elementos que inspeccionar del objeto o bien asegurado. En otras palabras, queda el riesgo traspasado por la emisión del certificado de cobertura de la aseguradora, provisorio o definitivo de los artículos 513 d) y e) del CCOM, dependiendo de su actividad precontractual de información. Es por ello que el certificado provisorio, ha de ser claro, preciso y ajustado a un lenguaje comprensible, tal y como debe ser el comportamiento y la información precontractual. Las consecuencias del incumplimiento de este deber, debieran reconducirse por no considerar como parte integrante de la cobertura aquello que no se explicite de manera clara y precisa y, por lo tanto, no vinculante para el tomador. Es cierto que el Certificado de cobertura pertenece a una fase contractual, sea este provisorio o definitivo de los artículos 513 d) y e) del CCOM, y que debiera ser posterior a la cotización que es estrictamente precontractual, pero su materialización le encadena con el certificado definitivo, la propuesta y la póliza, por lo que todo el deber de información previo a la aceptación ya ha concluido, esto significa que necesariamente se deberá haber informado al tomador todo lo que manda la ley 19.496 y el Código de Comercio, antes del perfeccionamiento del contrato de seguro, y de acuerdo a las fuentes que tuvo en mente el legislador chileno, en este trabajo analizadas, por escrito, de modo claro, comprensible y simple.

\section{BIBLIOGRAFÍA CITADA}

Arellano Iturriaga, Sergio (2013): La ley del seguro (Santiago de Chile, LegalPublishing Thompson Reuters).

Barrientos, Marcelo (2008): Daños y Deberes en las Tratativas Preliminares de un Contrato (LexisNexis).

\footnotetext{
70 Tirado Suárez (1990) p. 133.

71 Campuzano (2008) p. 116.
} 
Bataller, Juan, Latorre, Nuria y Olavarria, Jesús (2007): Derecho de los Seguros Privados (Madrid, Editorial Marcial Pons).

Beckmann, Roland (2009): Versicherungsrechts-Handbuch. (Verlag c.h. Beck München).

Bin, Marino (1993): Informazione e contratto di assicurazione (Rivista Trimestrale di Diritto e procedura Civile).

Bruck, Ernst (1930): Das Privat-Versicherungsrecht (Bensheimer Mannheim - Berlin) 819 pp.

Campuzano, Herminia (2008): El cumplimiento del Deber de Declaración del Riesgo. (Revista de Derecho Patrimonial. Civitas): pp. 116.

Claude, Jorge (2012): en Revista Mercado Asegurador. Argentina. N³86, p. 56-59 [fecha de consulta: 10 de julio de 2014].

Contreras Strauch, Osvaldo (2014): Derecho de Seguros, Segunda Edición (Santiago, Editorial LegalPublishing, Thomson Reuters).

De la MaZa, Iñigo (2013) "Articulo 17 B (Letras A, B, C, D, E, F)" en La protección de los derechos de los consumidores, Comentarios a la ley de protección a los derechos de los consumidores, Iñigo de la Maza Gazmuri y Carlos Pizarro Wilson Directores, Francisca Barrientos Camus, Coordinadora, Santiago de Chile, LegalPublishing Thomson Reuters, 383 pp.

Díez-Picazo, Luis (2006): "Contratos de consumo y derecho de contratos", Anuario de Derecho Civil, Tomo LIX, Fascículo I: p. 14

Díez-Picazo, Luis (2007): Comentarios a la Ley sobre Condiciones Generales de la Contratación. Obra colectiva. (Civitas) $511 \mathrm{pp}$

Domínguez Luelmo, Andrés (2012): "Derecho de desistimiento", en La revisión de las normas europeas y nacionales de protección de los consumidores, Sergio Cámara Lapuente (Director) Esther Arroyo Amayuelas (Coordinadora) (Madrid, Civitas Thomson Reuters) pp. 214 y ss.

Del Caño, Fernando (1983): Derecho Español de Seguros, Tomos I y II, 3ra. ed. (Madrid, Imprenta Sáez) 436 pp.

Donati, Antigono (1954): Trattato del Diritto delle Assicurazionni Private. Volume Secondo (Editore Guiffré) 561 pp.

Eichler, Hermann (1966): Versicherungsrecht. Karlsruhe, Deutschland.

Elguero, José María (2004): El contrato de Seguro (Fundación Mapfre) pp. 9 y ss.

Espada Mallorquín, Susana (2013): “Articulo 40", en Iñigo de la Maza Gazmuri y Carlos

Pizarro Wilson (Directores), Francisca Barrientos Camus (Coordinadora), La protección de los derechos de los consumidores, Comentarios a la ley de protección a los derechos de los consumidores (Santiago, LegalPublishing Thomson Reuters) 195 pp.

FALLON, M. y FrancQ, S. (2000): “Towards internationally mandatory directives for consumer contracts?" (eds. BASEDOW, J. y otros) en Private Law in the International ArenaLiber Amicorum Kurt Siehr (TMC Asser Press, The Hague) pp. 156

Fundación Mapfre (2013): El Mercado Asegurador Latinoamericano 2012-2013, Instituto de Ciencias del Seguro (Madrid, Fundación Mapfre) pp. 63 y siguientes. La NCG 347 Disponible en www.svs.cl Diccionario Mapfre de los seguros Disponible en http:// www.mapfre.com/wdiccionario/terminos/vertermino.shtml?c/contratante.htm, [fecha de consulta: 19 de julio de 2014.] 
Garrigues, Joaquín (1982): Contrato de Seguro Terrestre (Madrid, Imprenta Aguirre) 10 pp. Ghersi, Carlos Alberto (2007): “Contrato de Seguro" (Buenos Aires, Ed. Astrea) 169 pp.

Lambert-Faiure, Yvonne (1973): Droit des Assurances (París, Dalloz).

Munar Bernat, Pedro (2002): La directiva sobre contratos a distancia en materia de servicios financieros en Estudios jurídicos en homenaje al profesor Luis Díez-Picazo, pp. 1189 y ss

PAsquau Liaño, M. (2009): “Comentarios al artículo 6.2 CC”, Jurisprudencia civil comentada. Código Civil, tomo I (Granada, Gomares 2009) pp. 58-66.

Pérez de Madrid Carreras, Valerio (2012): "La protección del consumidor en la contratación bancaria”, Miranda Serrano Luis María Pagador y López Javier (Coordinadores), en Derecho (privado) de los consumidores (Madrid, Marcial Pons) pp. 427 y ss.

ReHBerg (2003): Der Versicherungsabschluss als Informationspro-blem (VersWissStud, Bd. 23, Bade-Baden) 224 pp.

Ríos Ossa, Roberto (2014): El deber precontractual de declaración de riesgo (Santiago de Chile, Editorial Thomson Reuters La Ley, LegalPublishing) pp. 20 y siguientes.

Rubio, Pedro (2003): El deber Precontractual de Declaración del Riesgo en el Contrato de Seguro (Fundación Mapfre) p. 15.

SÁnchez Calero (2001): Ley de contrato de seguro: comentarios a la Ley 50/1980, de 8 de octubre, y a sus modificaciones (Editorial Aranzadi. Navarra, España) pp. 96-97.

SÁnchez Calero (2005): "Caracteres generales de la Ley de Contrato de Seguro", Revista Española de Seguros n ${ }^{\circ}$ 123-124: pp. 61.

Sánchez Calero, Fernando (1980) "Las Condiciones generales en los contratos de seguro y la protección a los consumidores”, Revista Española de Seguros: pp. 6-7.

Sandoval, Ricardo (2004): Derecho del Consumidor. (Editorial Jurídica de Chile) 247 pp.

Schulze, Reiner (2006): "Deberes precontractuales y conclusión del contrato en el Derecho contractual Europeo", Anuario de Derecho Civil, Tomo LIX, Fascículo I: pp. 34.

Shavell (2000): "On the social Sinction and the regulation of liability insurance", The Geneva Papers on Risks and Insurance, 2000, rol. 25, n. ${ }^{\circ}$ 2, Oxford: pp. 166 a 179.

Solimando, Ángela (2001): Disciplina delle Dichiarazioni Precontratuale nel Contratto di Assicurazione. Evoluzione della Guirisprudenza (Assicurazioni) pp. 21-52.

STUYCK Jules (2012): "Las directivas en revisión y otros ámbitos necesitados de ulterior armonización”, Sergio Cámara Lapuente (Director) Esther Arroyo Amayuelas (Coordinadora), en La revisión de las normas europeas y nacionales de protección de los consumidores (Madrid, Civitas Thomson Reuters) 168 pp.

Tapia Rodríguez, Mauricio y Valdivia, José Miguel (2002): Contrato por adhesión. Ley $N^{o}$ 19.496 (Santiago, Editorial Jurídica de Chile).

Tirado SuÁrez, Francisco Javier (1990): “Anotaciones al Deber de Declaración del Riesgo en el Contrato de Seguro", Revista Española de Seguros: pp. 133.

URIA, Rodrigo (1962): Derecho Mercantil (Madrid, Imprenta Aguirre).

Veiga Copo, Abel (2013) "El riesgo: análisis y estudio crítico de la causa del contrato de seguro", Mariano José Herrador Guardia (Director), en Derecho de daños (Madrid, Thomson Reuters Aranzadi) 642 pp.

VeIga Copo, Abel (2008) Condiciones en el Contrato de Seguro (Editorial Comares) 455 pp. 
Volpe, Giovanna (2010): Comentario Breve al Diritto delle Assicurazioni (Cedam) 894 pp.

\section{NORMAS CITADAS}

Code of LAWS of the United States of America (U.S. Code). Véase en http://www.consumerfinance.gov/regulations/ [Fecha de consulta: 10 de julio de 2014].

"Consumer Financial Protection Bureau". Véase en http://www.consumerfinance.gov/ [fecha de consulta: 10 de julio de 2014].

Directiva 2002/65/CE del Parlamento Europeo y el Consejo, relativa a la comercialización a distancia de servicios financieros destinados a los consumidores. http://europa.eu/ legislation_summaries/internal_market/single_market_services/financial.htm [fecha de consulta: 10 de julio de 2014].

FEDERAL DEPOSIT INSURANCE CORPORATION (véase en http://www.fdic.gov/regulations/laws/ rules/6500-200.html\#fdic6500103) [fecha de consulta: 10 de julio de 2014], y en http://www.consumidor.ftc.gov/articulos/s0110-seguro-de-credito [fecha de consulta: 10 de julio de 2014].

Financial Services Act Office of Fair Trading Consumer Credit Act Disponible en http://www. oft.gov.uk/;jsessionid=FC66F46411B816C0CD480F141D3E3097 (fecha de consulta 3 de octubre de 2013) y Disponible también en http://www.oft.gov.uk/about-the-oft/ legal-powers/legal/cca/Precontractinformation\#.Uk24h9IagpU (fecha de consulta 3 de octubre de 2013).

Gesetz über den Versicherungsvertraghttp://www.gesetze-im-internet.delvvg_2008/_7.html [fecha de consulta: 19 de julio de 2014]. Verordnung über Informationspflichten bei Versicherungsverträgen Disponible en http://www.gesetze-im-internet.de/vvg-infov/ [fecha de consulta: 19 de julio de 2014].

Ley española 30/1995, de 8 de noviembre de ese año, de ordenación y supervisión de los seguros privados.

Ley española 50/1980, de 8 de octubre, de contrato de seguro.

Ley española 22/2007, de 11 de julio, sobre comercialización a distancia de servicios financieros destinados a los consumidores.

\section{JURISPRUDENCIA CITADA}

Servicio Nacional del Consumidor con Cencosud Administradora de Tarjetas S.A. (2013): Corte Suprema, Recurso de Casación en el fondo en autos sobre infracción a la Ley $\mathrm{N}^{\circ}$ 19496, sentencia de veinticuatro de abril de dos mil trece, Rol: 12.355-11.

Superintendencia de Valores y Seguros contra BBVA Corredores de Bolsa (2009): Corte de Apelaciones de Santiago, Recurso de apelación en contra de la sentencia definitiva, sentencia de veintitrés de octubre de dos mil nueve, Rol: 1322-2008, N LegalPublishing: 42742 . 
